التعريف الإجرائي للعلاقة بين البحث والتدريس الجامعي: دراسة تحليلية لعينة مختارة من الدراسات السابقة

\author{
* أحمد سليمان موده \\ جامعدة جدارا، اريد، الأردن

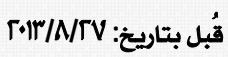

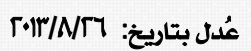

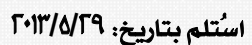

\begin{abstract}
تكشف قوائم ترتيب الجامعات وتصنيفها التي تصدرها الهيئات الدولية المتخصصة عن إختلافات جوهرية ِِّ2 مدى تحقيق معايير ذات صلة

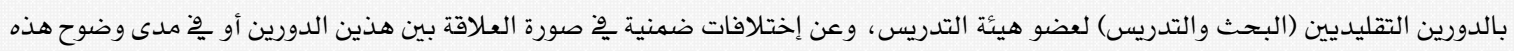

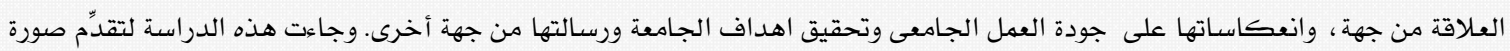

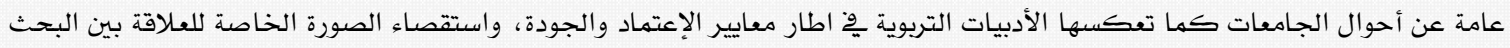
والتدريس كما تعكسها الدراسات التي تتاولت هذين الدورين على مدار أكثر من ستين عاما مضت حتى تاريخه. وقد أشارت نتائج التحليل التتبعي لعينة الدراسات التي امكن الوصول اليها الى طيف واسع من التعريفات الإجرائية للعلاقة بين الدورين، وإلى جملة من السلبيات

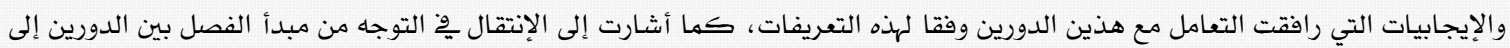

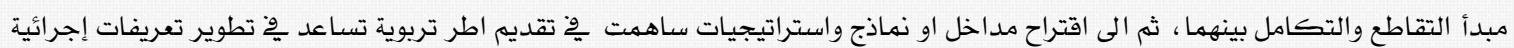

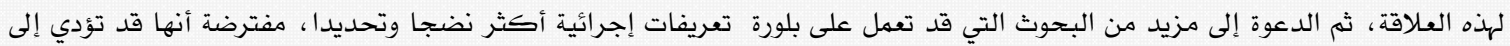

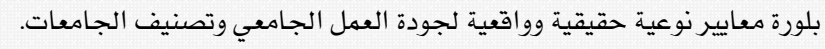
كلمات مفتاحية: البحث، التدريس، العلاقة بين البحث والتدريس، رسالة الجامعة، تصنيف وترتيب الجامعات، معايير الجودة، تعريف
\end{abstract} إجرائي.

\title{
O perational D efinition of the Relationship between University Teaching and Research: An Analytical Study of a Selected Sample of Previous Literature
}

A hmad S. Audeh*

Jadara University, Irbid, Jordan

lists of university classification and ranking issued periodically by quality assurance agencies reveal enough indicators of significant differences in verifying the standards related to the two main traditional roles (research and teaching) of faculty members. Literature reveals significant differences in the clarity of the relationship between the two roles and their implications or impacts on the quality of academic work. The study came to provide an overview of this relationship based on the results of chronological meta-analysis of a selected sample of published educational literature over the last sixty years, and an overview of the possible impacts of the embedded operational definition(s) of this relationship. The results indicated a significant change from mutually exclusive roles to some kind of interaction and integration between them with implicit and explicit change in the operational definition(s) of this relationship. Different approaches, models and strategies were proposed to enhance this relationship. Further research are required to crystallize typical operational definition of this relationship, and to encourage looking for more advanced and authentic qual itative standards in the process of university ranking and classification.

Keywords: research, teaching, relationship between research and teaching, university mission, university ranking and classification, quality standards, operational definition.

*prof_ahmad_audeh@yahoo.com 
-

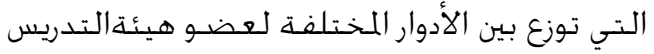

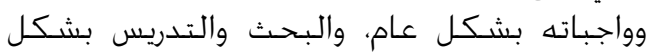

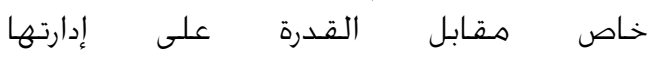
Time \& Task Managment

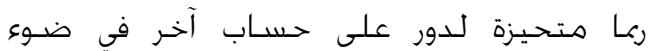

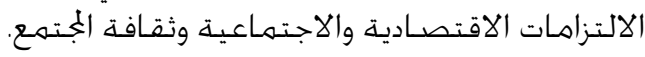
تركيز اللعايير الدولية لترتيب الجامعات وتصـنيفها

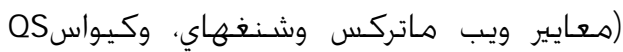

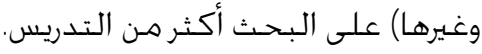

في ضـوء هذا التصـور، فإن العـلاقة بين البحـث والتـريس

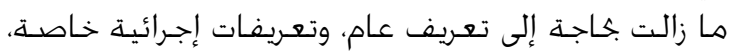

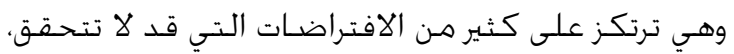

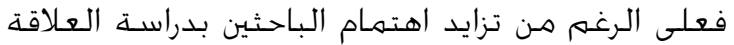

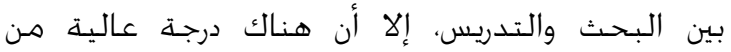

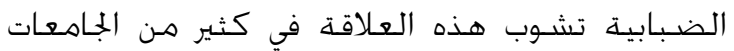

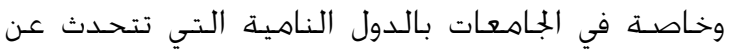

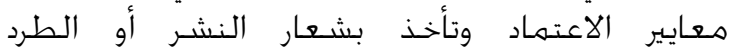
مع أن براهـ تطوير أداء الهيئة (Publish or Perish)

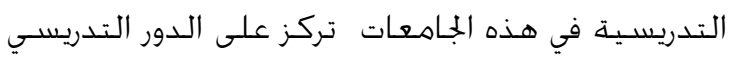

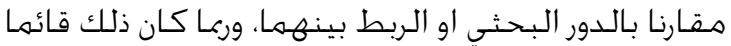

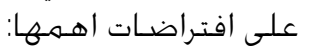

- أن الجامعة (أي جامعة) بالدرجـة الأولى تدريسية

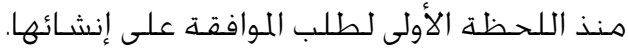

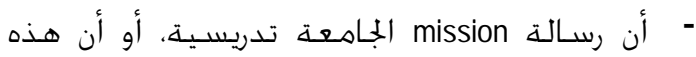
الرسـالة ترجـح أنها تدريسـيـة.

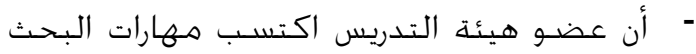

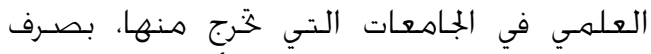

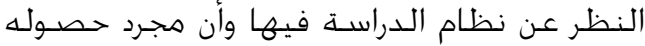
على الدرجـة العلميـة يكـون قد تأهل ليكـون باحثًا،

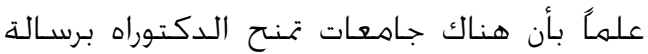

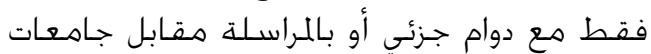

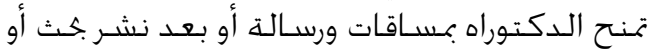

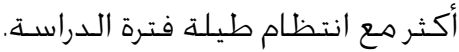

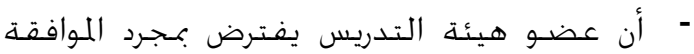
على تعيينه أنه اكتسب جـرعة كافية لأن يكون

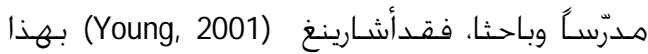

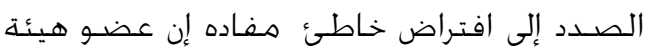

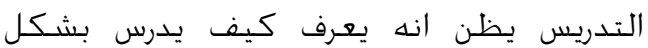

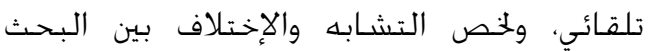

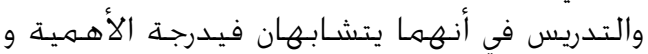
التعقيد، extremely important and complex activity

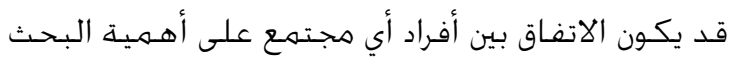

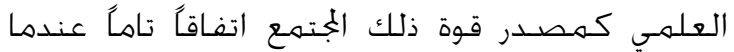

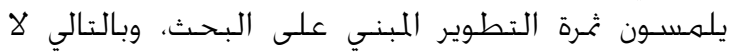

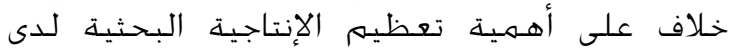

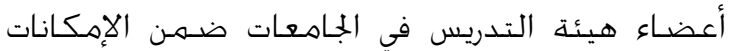

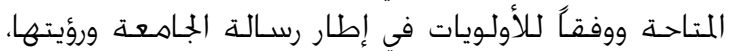

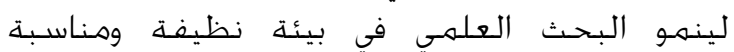
.Research-Land

وكمها تتزايد الضغغوط على الجـامعات للحصــول على الاعتمـاد وأخــ مـواقع لهـا في ترتيب Ranking الجـامعات

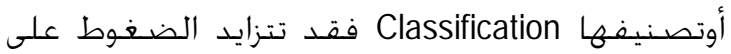

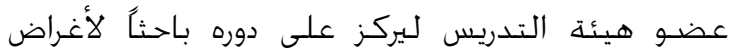

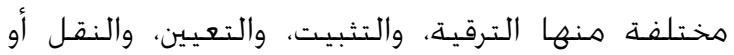

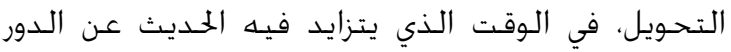

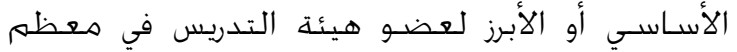

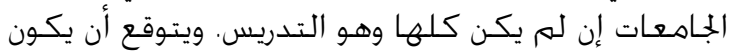

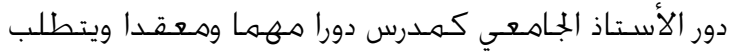

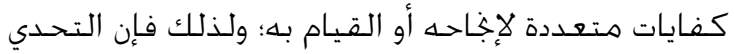
الكبير الذي يواجه الجامعات قبل الباحثين هو الخروج

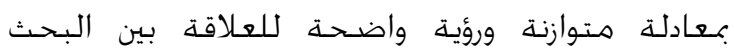
والتدريس. لتعظيم الأداء في الدورين وتقديم تعريف إجرائي للعلاقة بينهما. وعلى الرغـم من شـيوع الوصـف للأسـتاذ الجـامعي بأنه

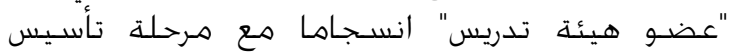

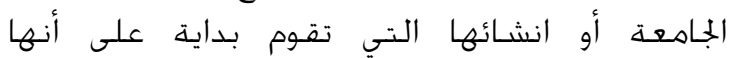

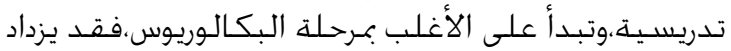

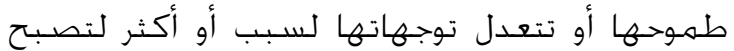
أكثر ميلاً لأن تكون بحثية محكوهة تعهول بعواهل منها:

تزايد أعداد الطلبة في الجامعة، نظرا لتعدد البراهـج

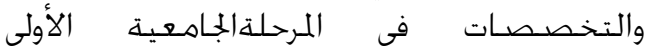
والدراسـات العليا.

تراجع شـروط قبول الطلبة في ضـوء الضغوط

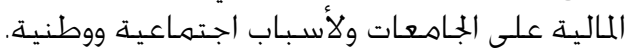
خضـوع التعيين لأعضاء هيئة التدريس للعايير

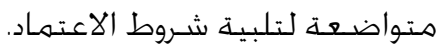
- التنوع في قدرات اعضـاء هيئة التدريس التدريسيـة

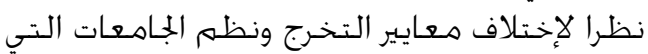
خترجوا هنها. تعـدد الأدوار الفـرعية واللمهارسـات والكفـايات في اطـار الدور التدريسـي وغموض معايير تقييم هـذه الأدوار. 


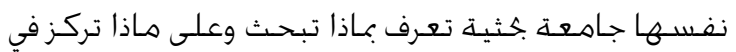

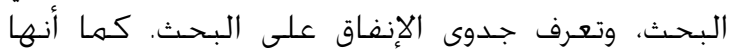

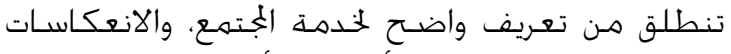

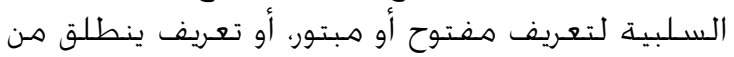

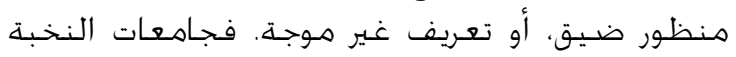

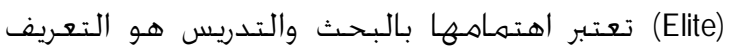

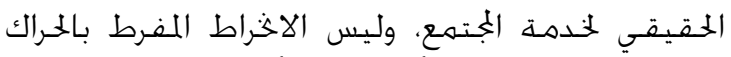

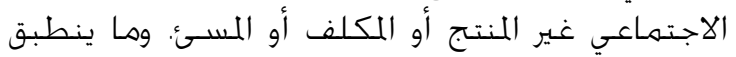

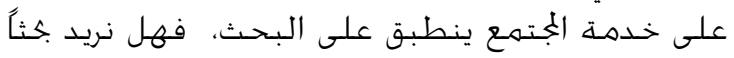

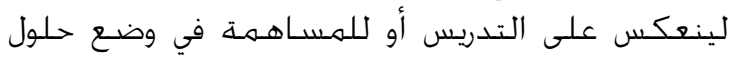

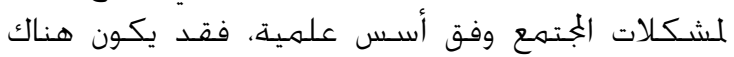

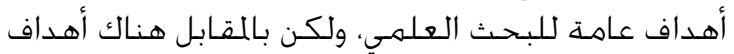

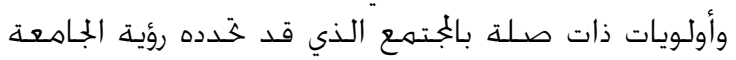

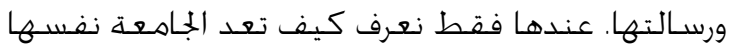

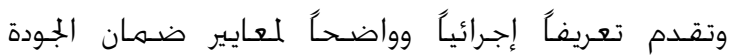

ومؤشـراته.

رافق حركة الاعتماد والجـودة وترتيب الجامعات وتصـنيفها،

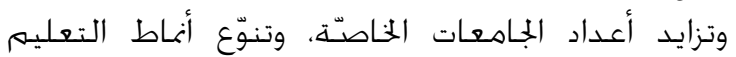

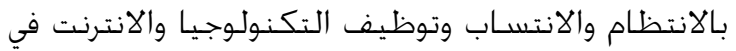

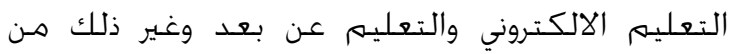

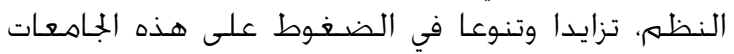
وبرامجها والعاملين فيها وخاصّة أعضاء هيئة التـدريس.

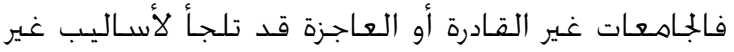

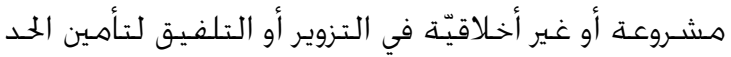

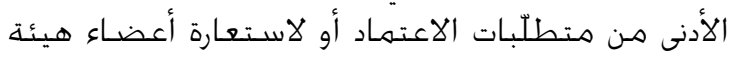

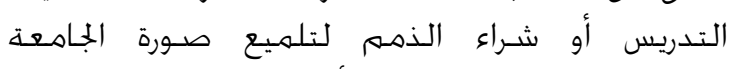

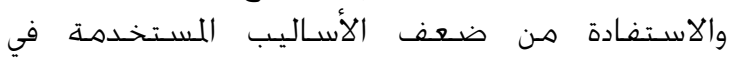

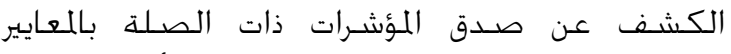

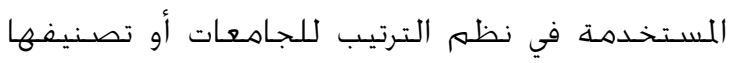
وانعكاسـاتها على البحثث والتدريس والعلاقة بينهما

هثل:

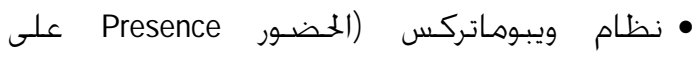

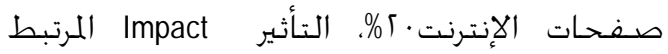

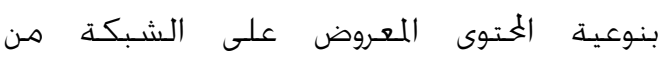

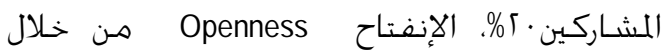

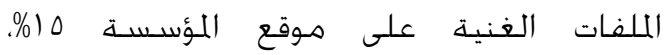

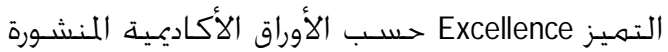

وذات رقم تأثير دوليه (1\%) حسن

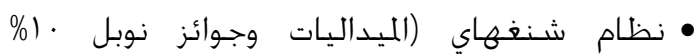

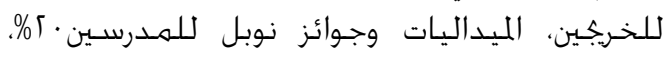

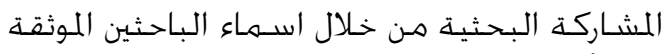

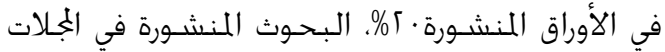

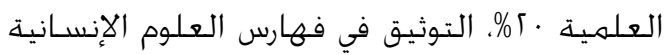

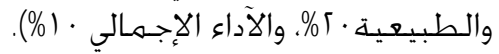

ويختلفـان في أن أعضـاء هيئة التدريس ينشـرون

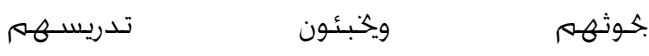
(Publish research but mute teaching) هيرسـت وكاهب (Hurst \& Camp, 1999) نظرا الى

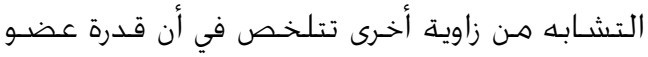

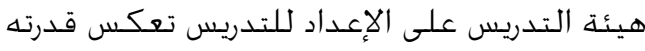

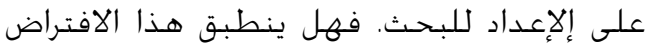

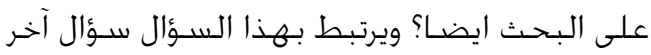

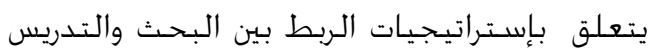

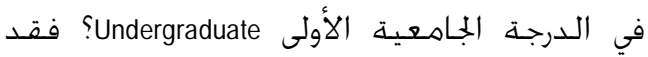

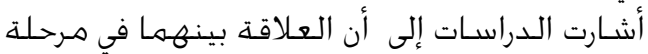

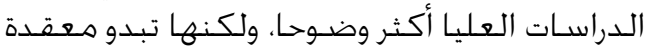
في المرحلة الجاهعية الأولى. الجيا.

تؤكـد المبادئ التربوية على أن الطالب يتعلهم مـن خلال

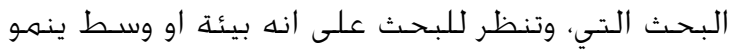

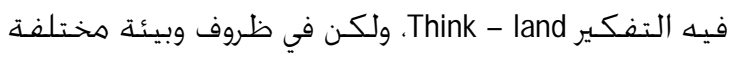

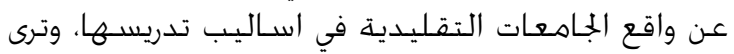

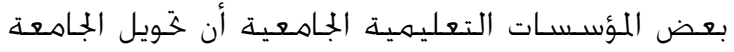

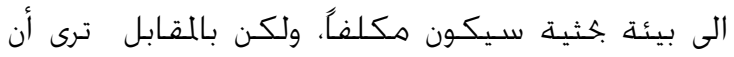

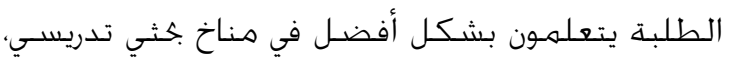

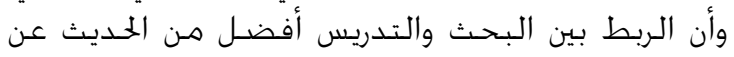

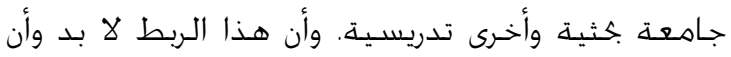

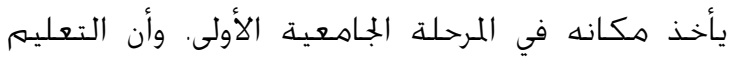

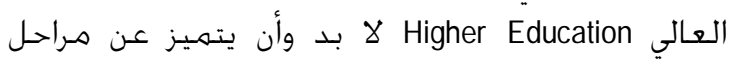

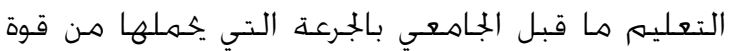

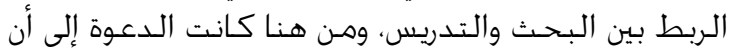

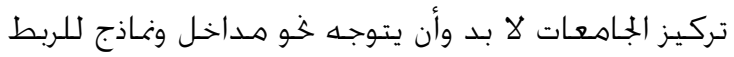

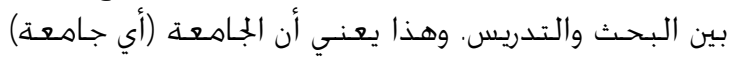

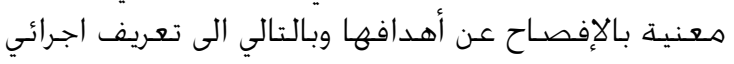
للعلاقة بين البحـث والتـدريس.

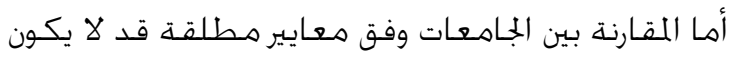

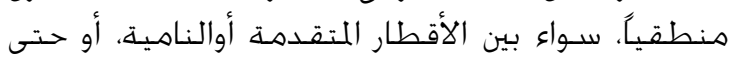

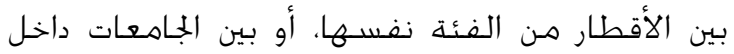

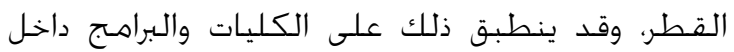

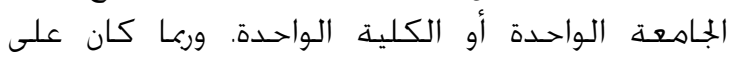

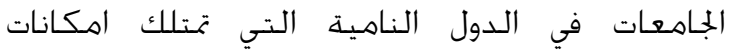
متواضعـة أن تنطلق هـن رؤية واضحـة وإرادة قوية، وإدارة

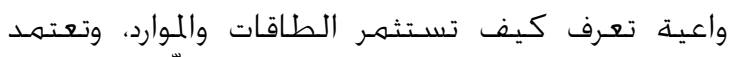

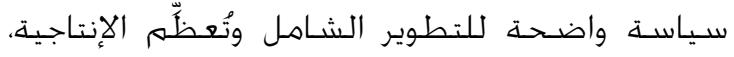

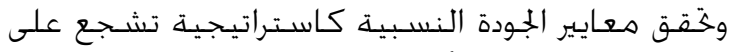

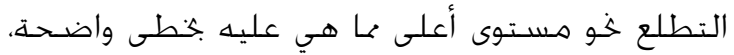

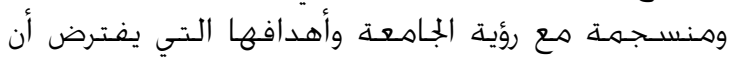

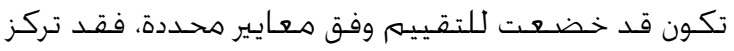

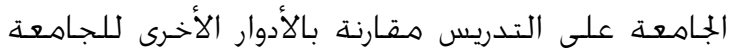

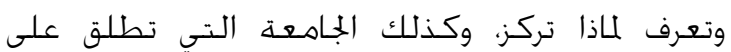




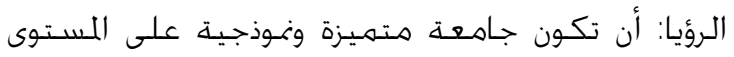

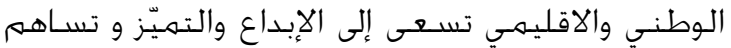

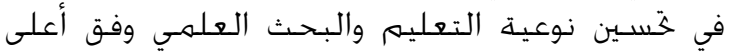
المستويات العالمية.

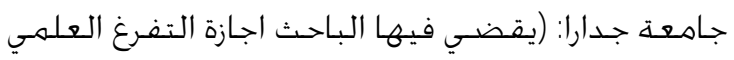

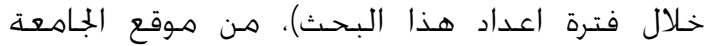
www.jadara.edu.jo

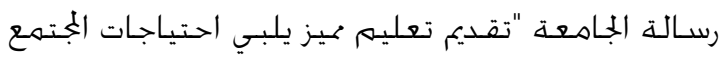

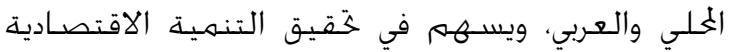

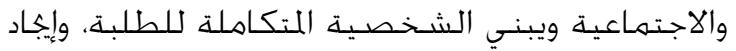

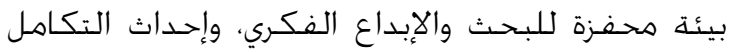

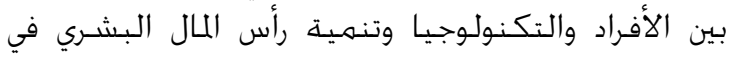

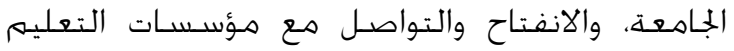
العـالي داخـل الوطن وخـارجـهـ.

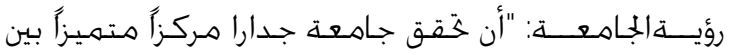

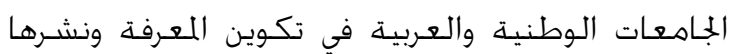

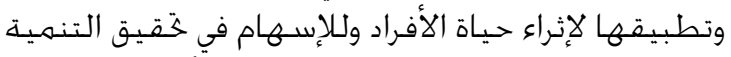

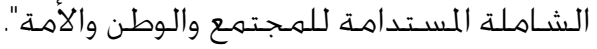

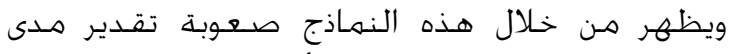

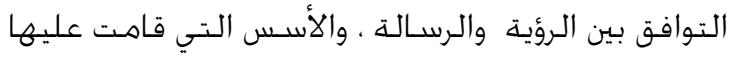

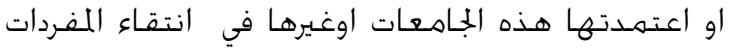

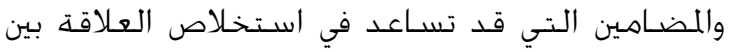

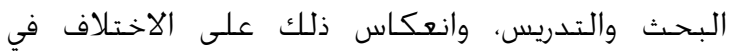

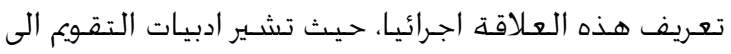

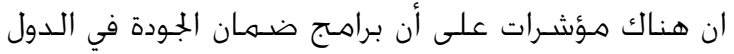

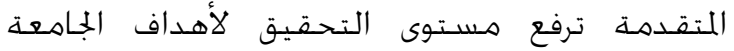

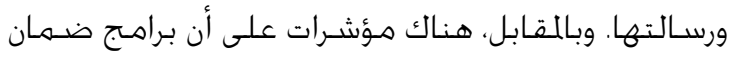

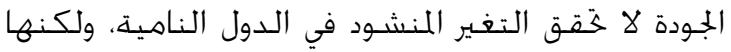

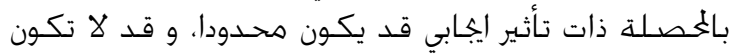
هذه البراهـج أكثر مـن هوس أو نزوة عابرة (Passing Fad) (David, 1999)

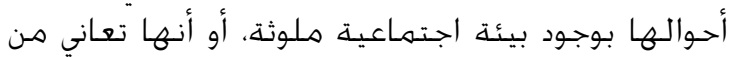

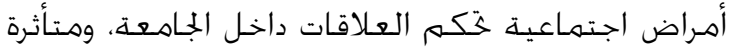

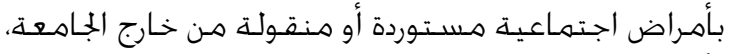

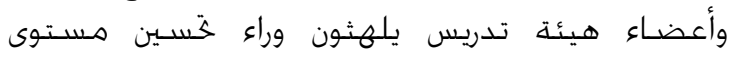

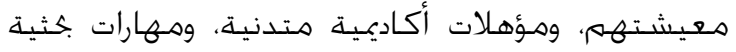

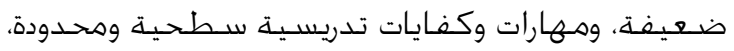
واهتمام أو انشغال بقضارات وكايات سياسية أو علاقات

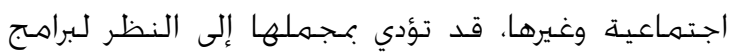

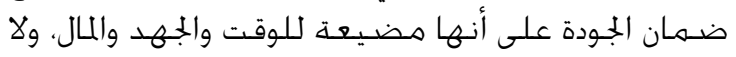

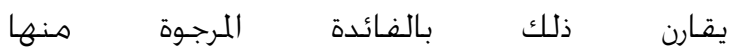
ويقتصـر جسمال البرنامـج (So much work for a little gain)

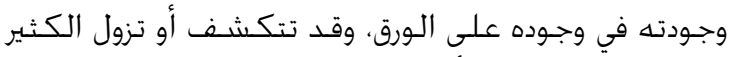

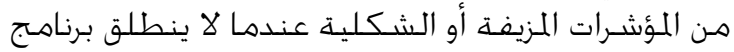

• نظظام كيو إس (أراء الأكاديميين · ع\%ة اراء المستخـدمين

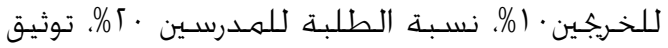

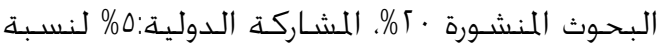

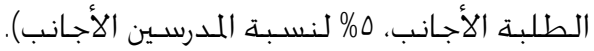

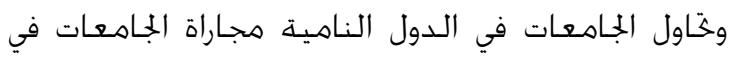
الدول المتقدمة لتنفيذ براهـج ضـمان الجهودة لتحسيـين

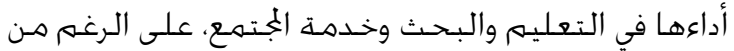

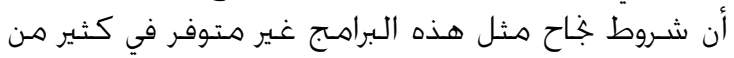

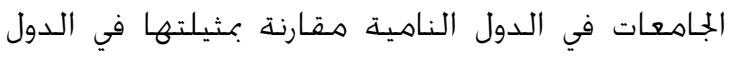

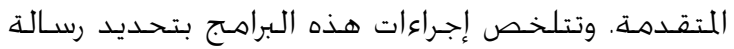

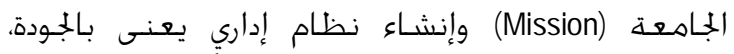

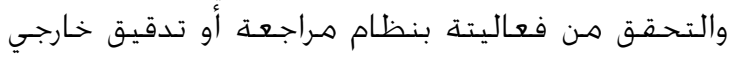

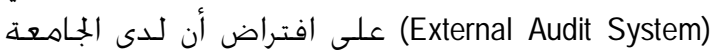

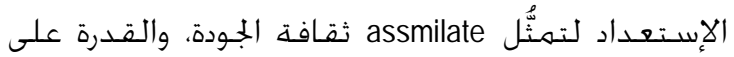
الالتزام واســـــرارية العمـل في هـذا الإطار (David, 1999)

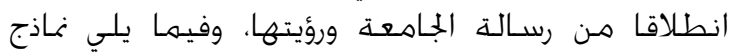

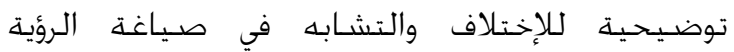

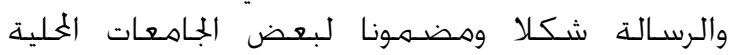

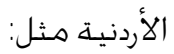

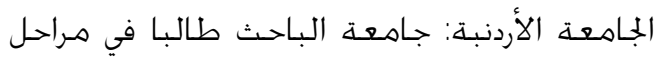

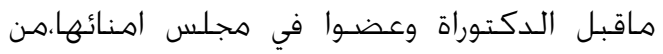

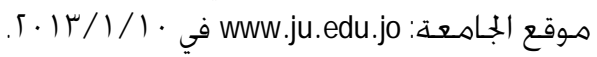

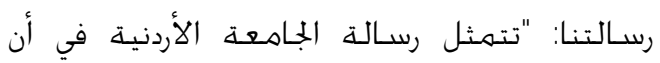
تصببح جامعة رائدة بين الجامعات المصنفة رلصة عالمياً.

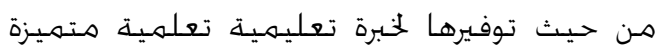

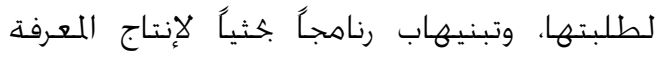

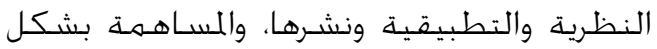

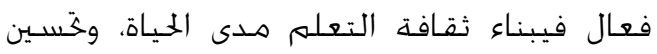

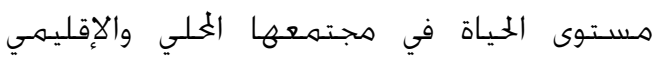
والعالمي" ملوي"

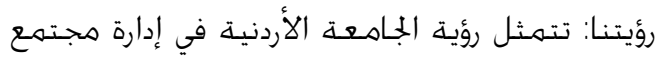

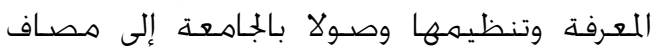

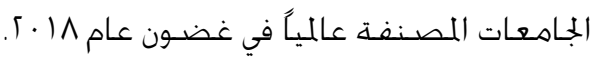

جامعة اليرمهوك: (الجامعة التي يعمل فيها

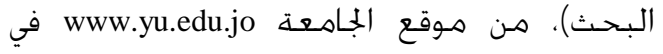
. $.1 \% / 1 / 1$.

الرسـالة: "التميز في التـريس والبحـث العلمي وخدمة

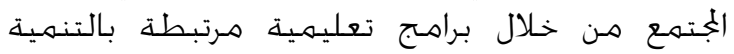

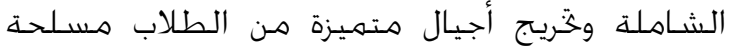

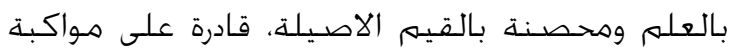

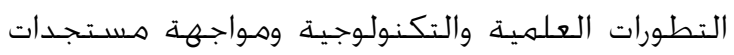
العصـر، والمنافســة على المســويين الاقليـهي والـدولي. 
0. هل تقـدم الدراسـات مؤشـرات كمية أم نوعية للعلاقة بين البحـث والتدريس؟ مؤس الترات

1. هل تعزز نتائج الدراسـات جـلية العلاقة بين

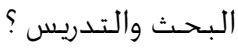

V. هل تقـدم الدراسـات ما يشـير الى علاقة متجهة

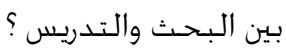

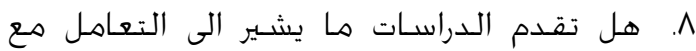

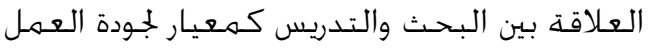

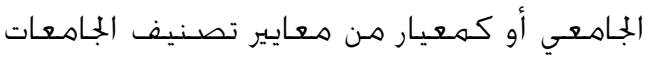

وترتيبـها؟

9. كيف تطورت العلاقة بين البحث والتدريس في

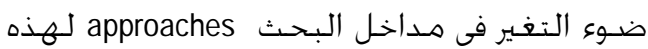

العلاقة؟

• (.ـها الصـورة المتوقعة لمستقبل العلاقة بين البحثث

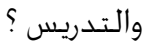

ll. كيف يمكن تضييق الفجوة Gap بين البحـث

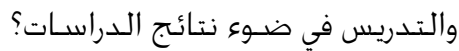
ז ا.ـهل هناك مايشـير الى ان أعضـاء هيئة التدريس

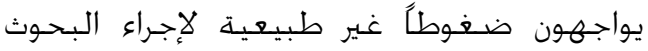

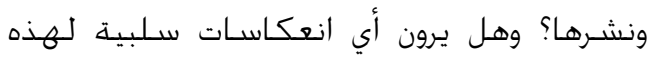
الضغنوطات ؟

\section{منهجية الدراسـة}

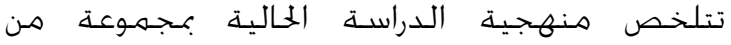

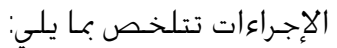

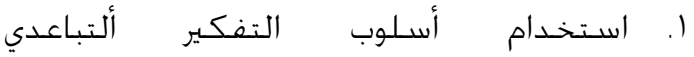
laundry في خخضير قائمة أولية divergent phase oـ list

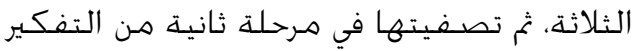
ألتقاربي divergent phase.

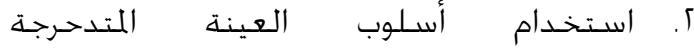
في البحث عن كلمات (sampling snowball)

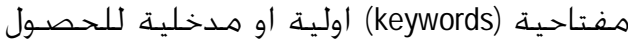

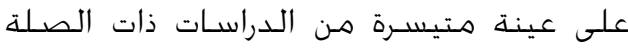

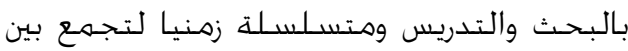
الحـداثة والشـمـولية.

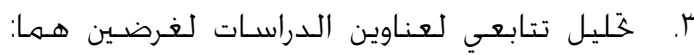

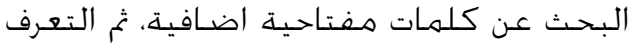

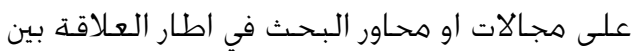
البحـث والتـدريس.

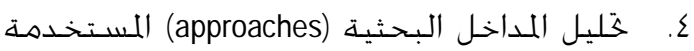

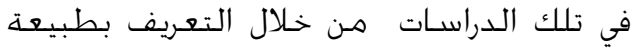

ضـمان الجـودة مـن قناعـات أو هـن مبادرات ذاتية، وخـاصــة

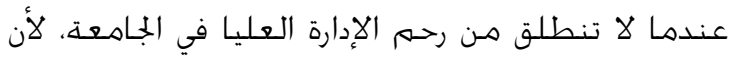

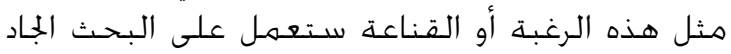

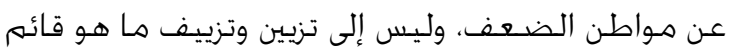

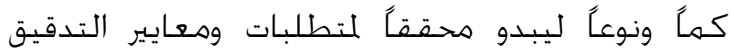

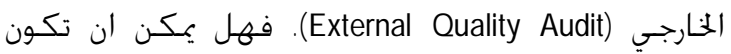

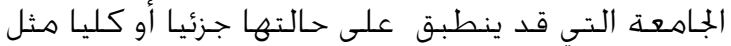

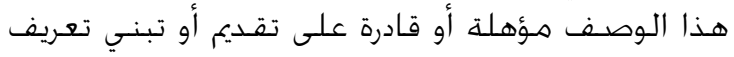

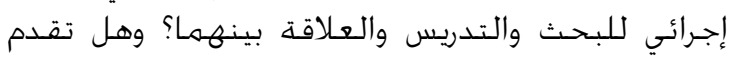

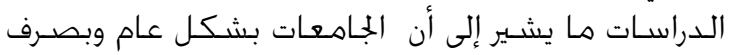
النظر عن موقعها وفق أي نظام تصـنيف قادرة على بلورة

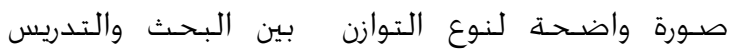

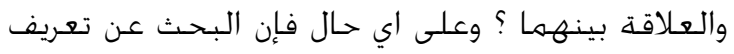

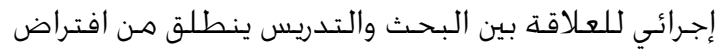
assumption

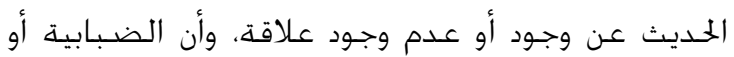

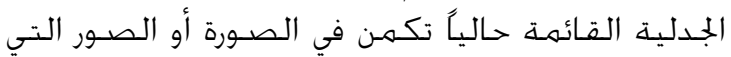

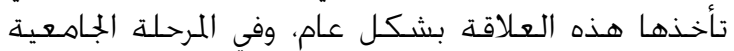
الأولى بشـكل خـاص.

\section{مشكلة الدراسـة}

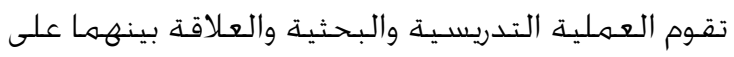

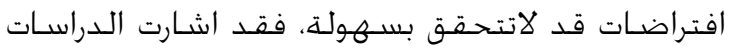

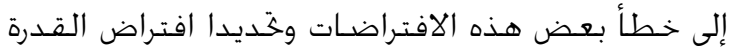

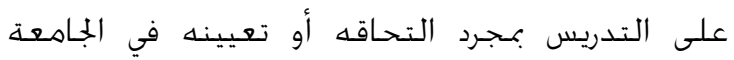

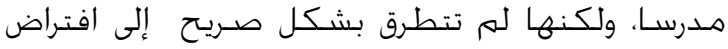

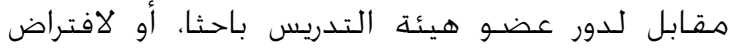

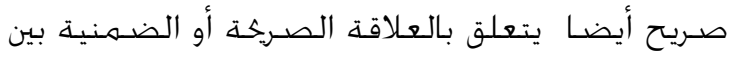

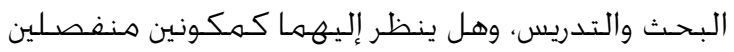

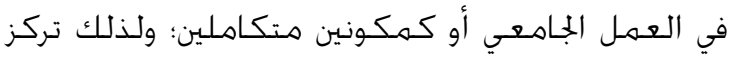

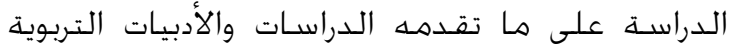

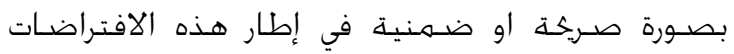
(الافتراض الخاص بالتدريس، والافتراض الخاص بالبحث.

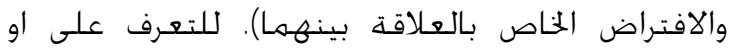

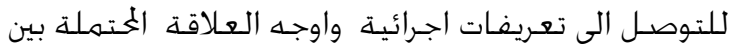
البـحث والتـديس هـن خـلال الإجابة عـن الأسئلة التاليـة: ا. . مـا أهـميـة البحثث في العلاقة بين البحـث والتدريس؟ ז. ما هي الغماور البحثية التي طرحتها الدراسـات

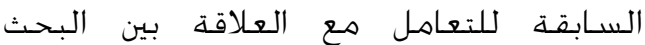
والتدريس؟

rا. ها هي العواهل او المتغيرات الغـددة للعلاقة بين

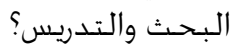

ك. هل تقدم الأدبيات والدراسـات السـابقـة تعريفا

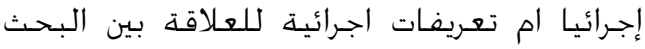
والتدريس؟ 
فقد ظهرت كلمات مسـاندة مثل:النشر او الإنهاء teach or sقابل التدريس او التجريح publish or perish

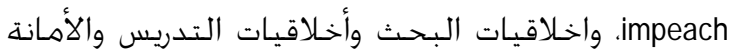
البحثية research misconduct and plagiarism وتعزيز

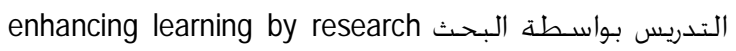
لعلاقتهما بالتفكير العلمي والتفكير الناقد والإبداعي critical and creative

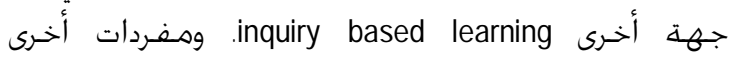

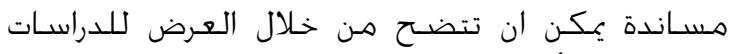

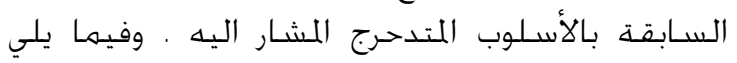

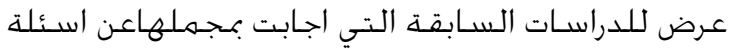

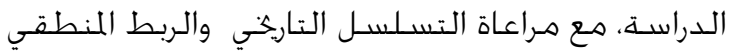

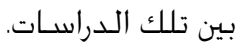

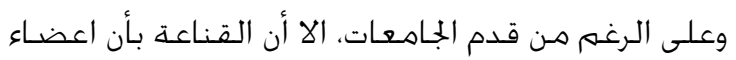

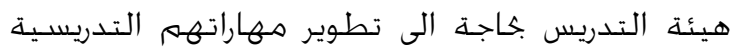

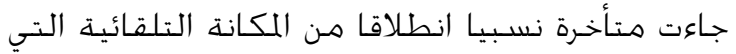

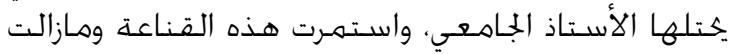

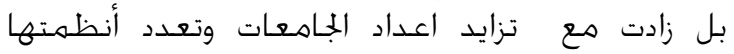

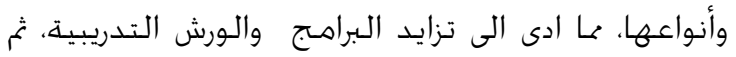

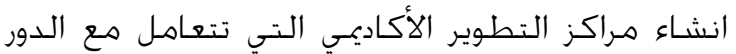

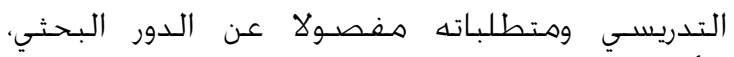

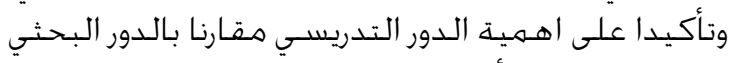

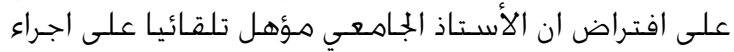

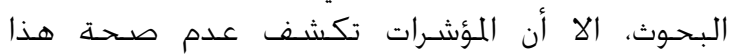

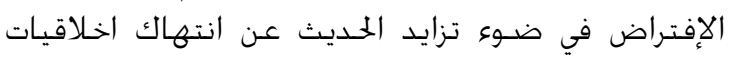

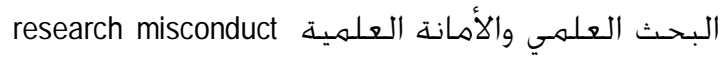

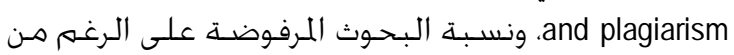

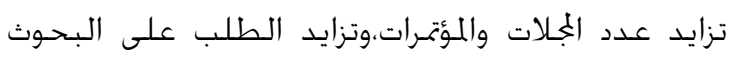
call for papers

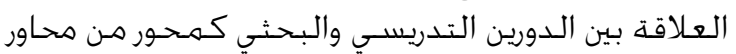

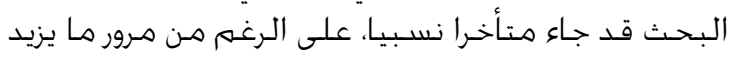
عن قرن ونصف على على ماء أشار إليه نيون نيوهان

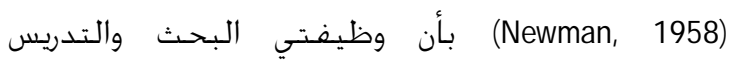

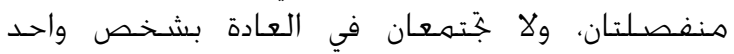

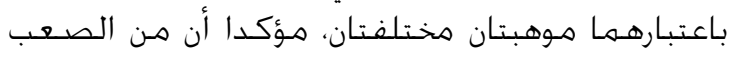

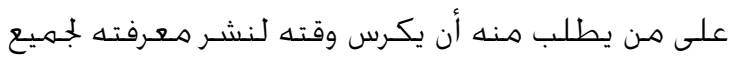

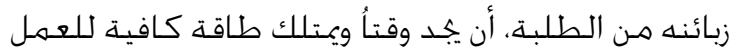

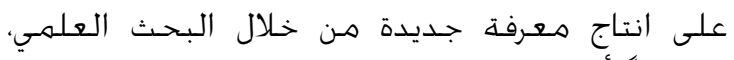

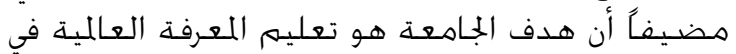

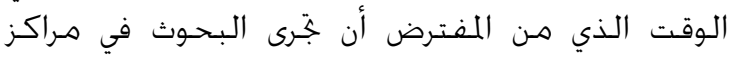

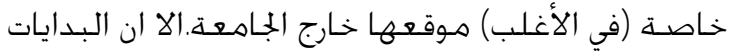

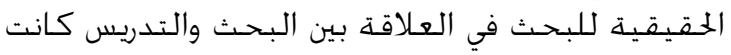

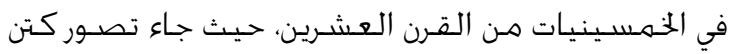

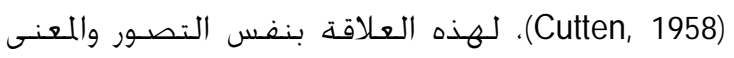

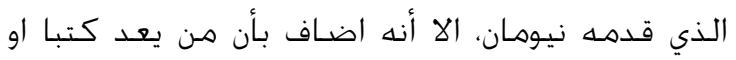

المشكلات البحثية والأسئلة او الفرضيات المطروحة.

0. خليل الدراسـات في ضـوء الأدوات المستخـدمة في جمع المعلومات وهصادرها.

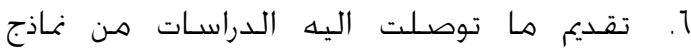

مقترحة او واقعية للربط بين البحث والتدريس.

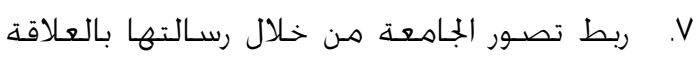
بين البحث والتدريس.

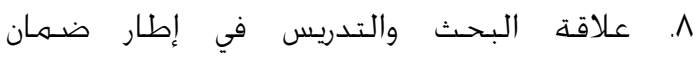
الجـودةوتصنيف الجامعات.

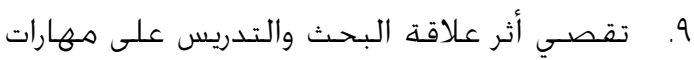
البحث ومتطلباته مقابل مهارات التخرئ التدريس مهارات ومتطلباته.

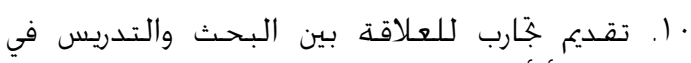
ضـوء ألأوجه الغتمعلة لهذهه العلاقة.

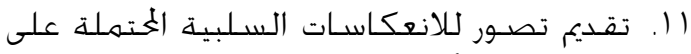
عدم التوازن أو الوضوح في العلاقة بين البحث والتدريس. I (. تقديم نماذج من فقرات اداة بحث في اطار العلاقة

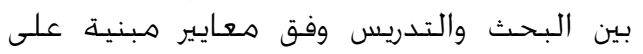
مجال مفتوح في تعريفه إلإجرائي.

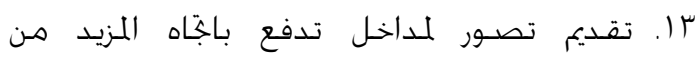
المساهمات البحثية في اطار العلاقة بين البحث لـاهي والتدريس.

الدراسـات السـابقة

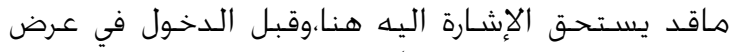

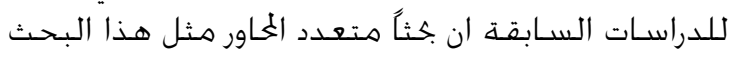

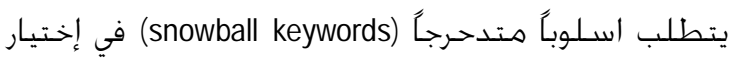

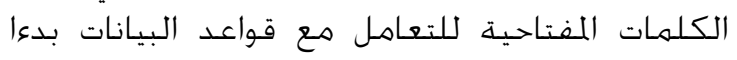
بكلمتي بكث(research)، وتدريس (teaching)، وانتهاء

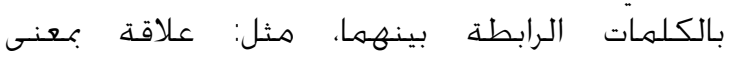

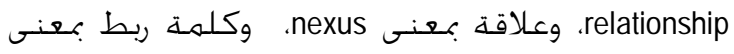

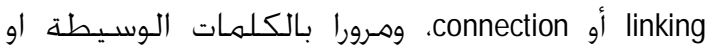

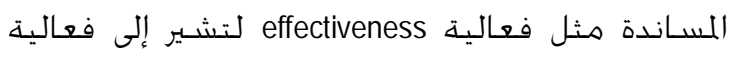

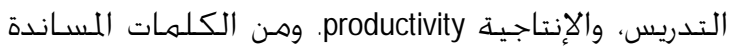

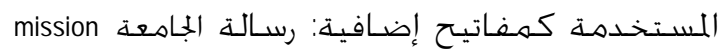

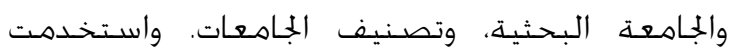

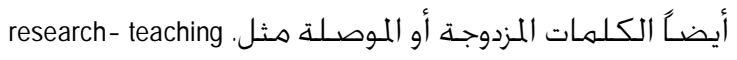
nexus, research- based teaching, teaching - based research

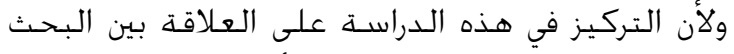

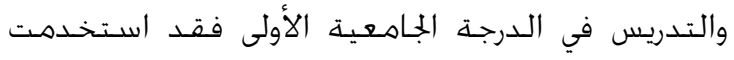

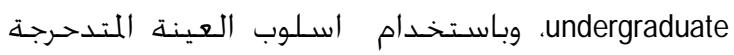


علاقة صفرية، واستنتج أن هذه العلاقة لا بد وأن تكون

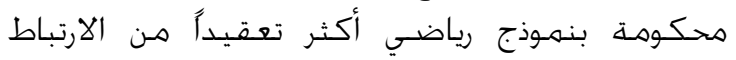
البسيط المباشر، فأضاف متغير الرتبة الأكاديمية. وتقديرات رؤسـاء الأقسـام لقدرات أعضـاء هيئة التدريس.

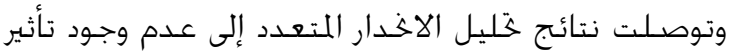

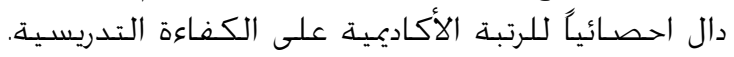
وباللقابل حاول فليدمان (Feldman, 1987) في دراستة التحانة

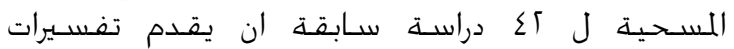

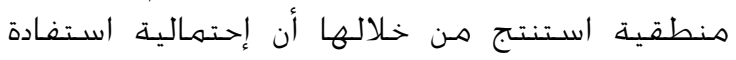
عضو هيئة التدريس من انتاجه البحثي في تدريسه إحنها

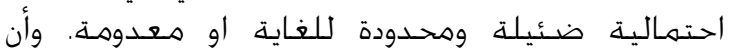

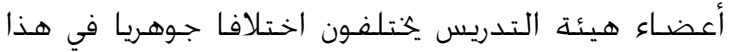

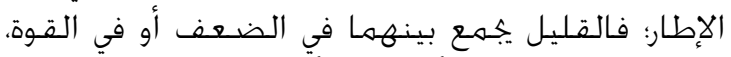

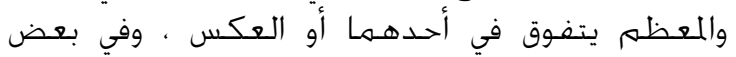

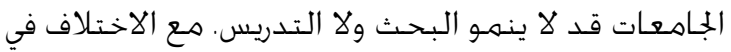
درجة تأثرهم ببعض لالئ القضايا مثل:

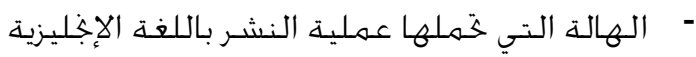
بصـرف النظر عن التخصص، او القدرة على كتابة

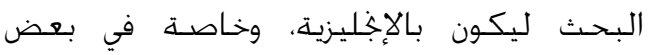

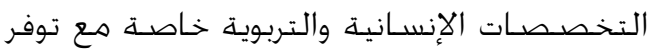

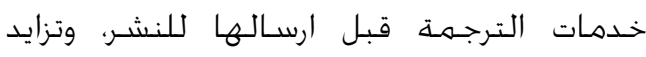

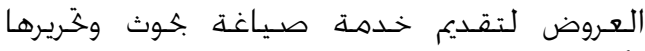
لأغراض النشر.

تزايد عدد الجامعات ورغبتها في اصـار مجلات. واستقطاب البحوث بأي مستوى لاصدار تلك الكار مجلك

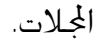

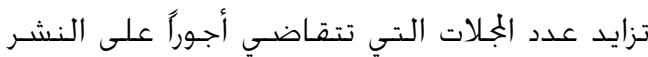

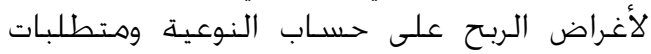
التحكيم والنشر.

- اخسـار فرص النشـر للشـك في مستوى الجملات.

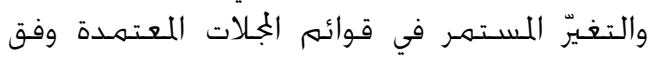

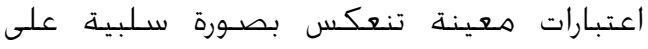
تكافؤ الفرص وعدالة القرارات، وعلى المناخ الجامعي البحثي والتدريسي والادراي والتنظيمي

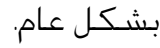

- - زيادة الإهتمام بعدد البحوث على حساب نوعيتها

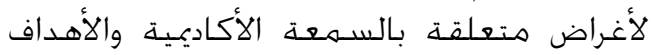

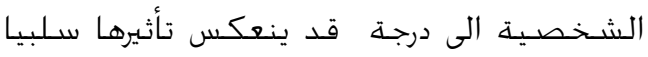

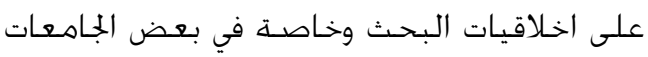
التي تسعى الى التميز الشكلي.

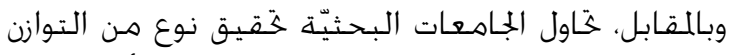

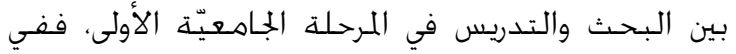

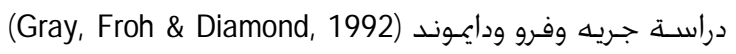

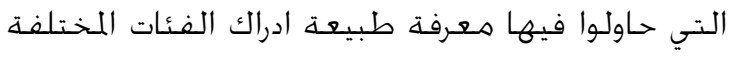

بحوثا يمكن ان يكون مدرسا افضل وليس العكس. وكانت

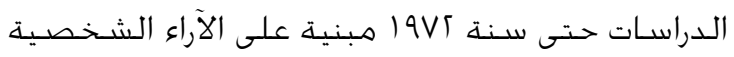

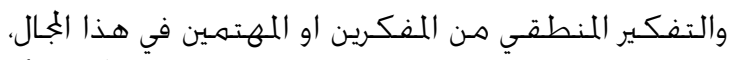

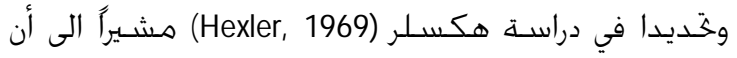

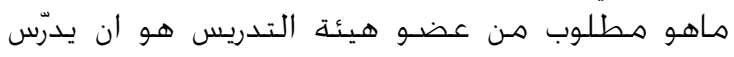

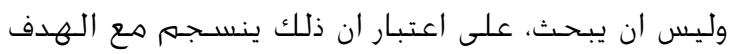

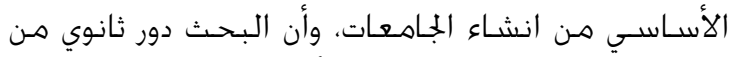

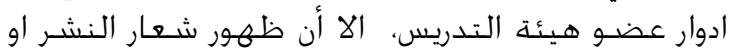
الطرد publish or perish خلال تلك الفترة دفع الباحثين

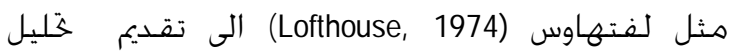
منطقي لهذا الشعار مبينا ماله من ايجابيات وماعليه

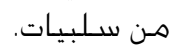

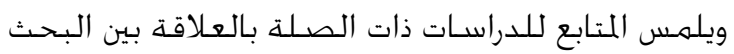

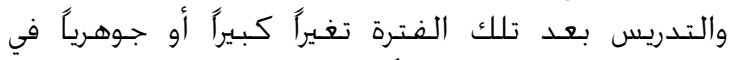

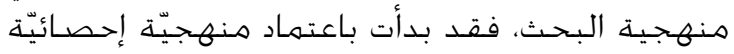

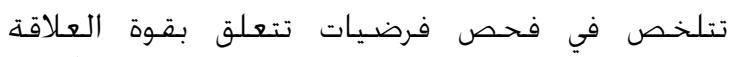

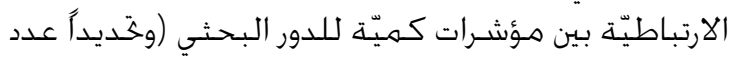

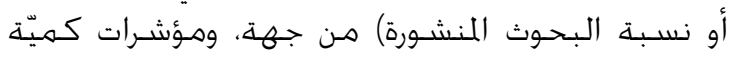

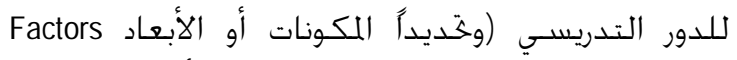

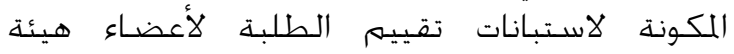

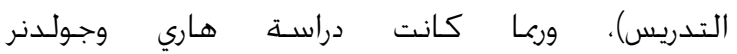
من الفئة الأقدم من هذارئ (Harry \& Goldner, 1972)

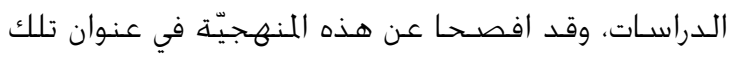

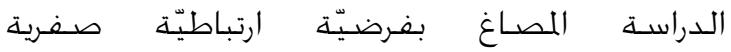
(Null relationship)

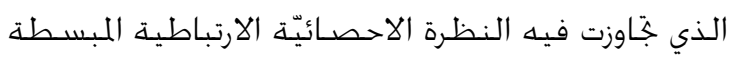

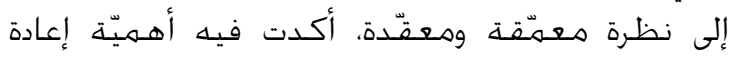

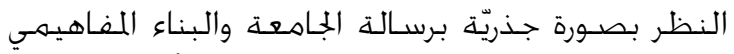

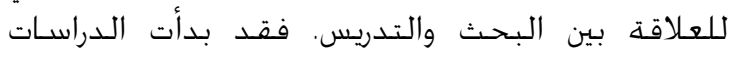

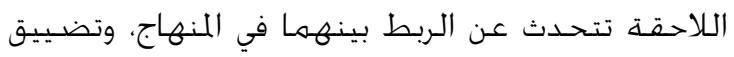

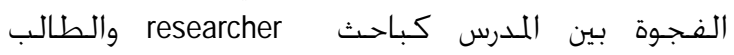

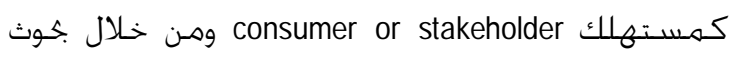
اجرائية action research يكون فيها الطالب مشاركا

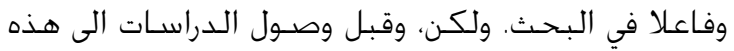

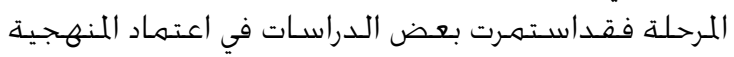

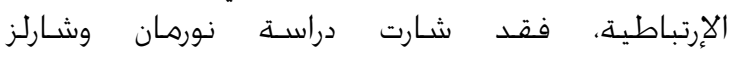
(Normanand Charles, 1976)

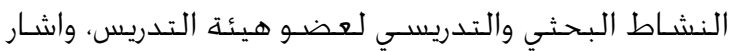

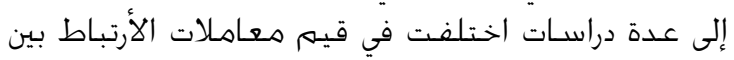

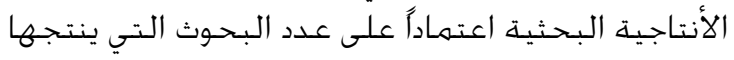

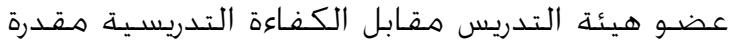

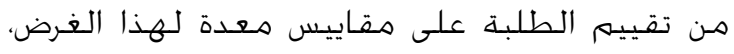

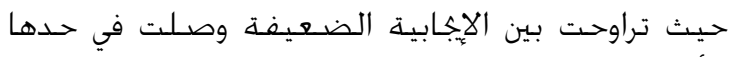

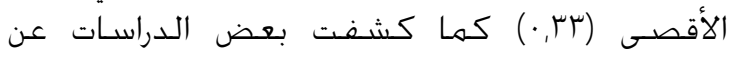

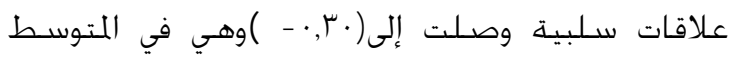




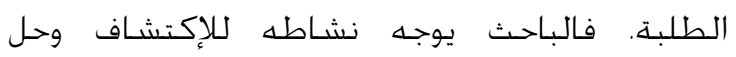

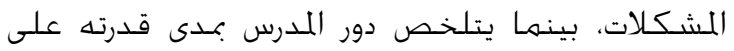

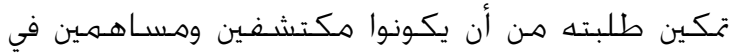

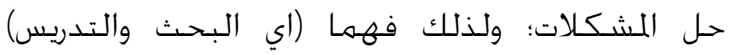

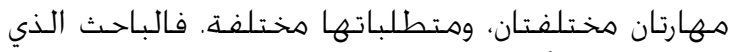

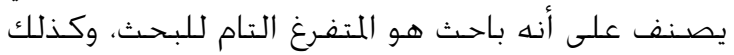

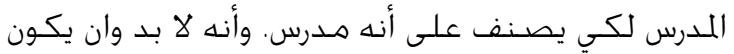

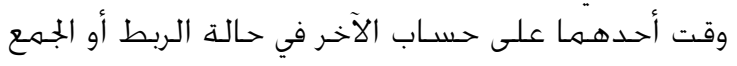
بينهما. فقد اشار هيتي ومارس (Hattie \& Marsh, 1996)

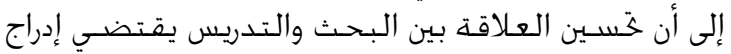

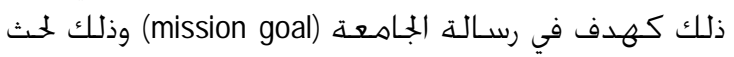

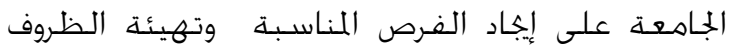

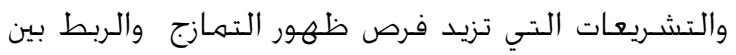

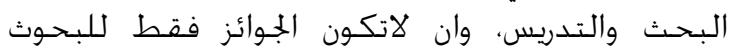

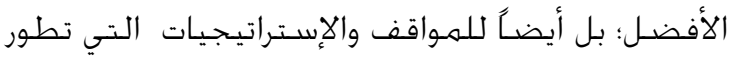

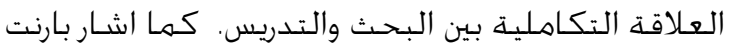

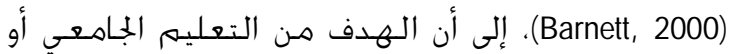

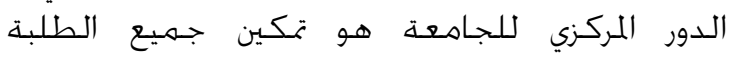

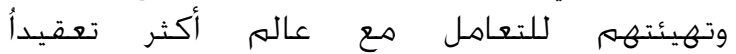
(super complexity world)

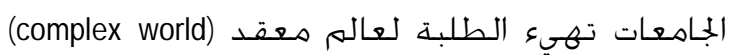

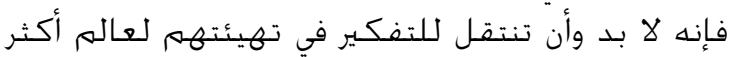

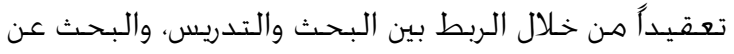
إستراتيجيات لتعزيز هذه العلاقة.

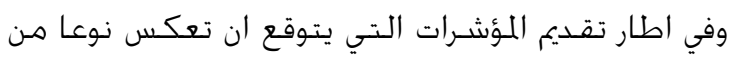

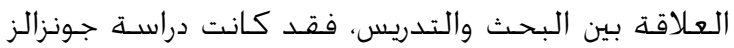
(Gonzalez, 2001)

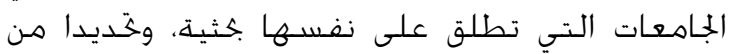

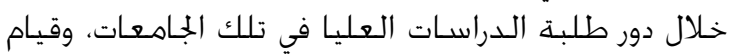
بعضها بعقد مؤتمرات أو ندوات سـنويّة في هذا الهـات الإطار.

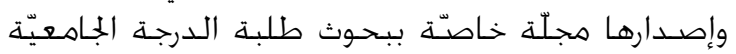

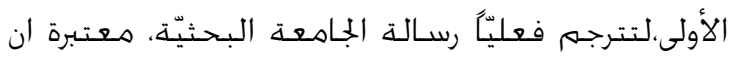
تدريب الطلبة على اجراء البحوث هو التعريف الإجرائي

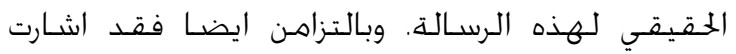

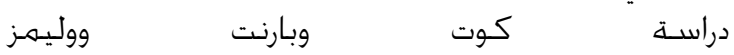
إلى أن التدرج المدروس (Coate, Barnett, \& Williams, 2001)

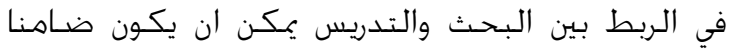

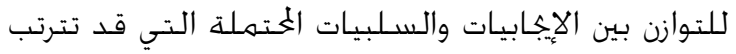

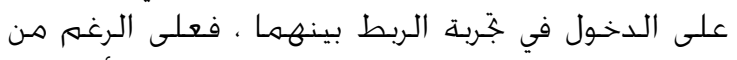

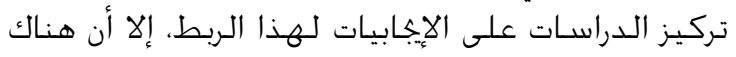

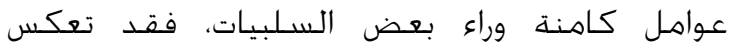

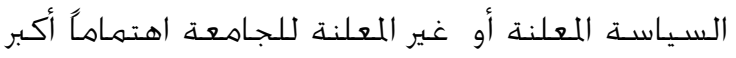

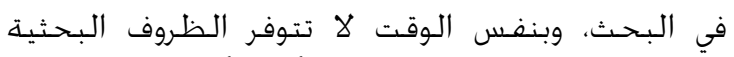

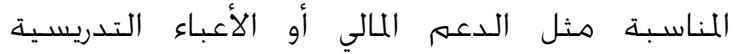

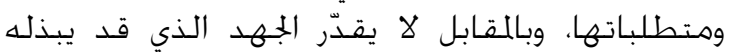

من أعضاء هيئة التدريس والإدارة الجامعيّة للأهميّة

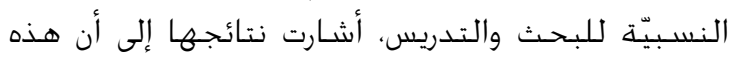

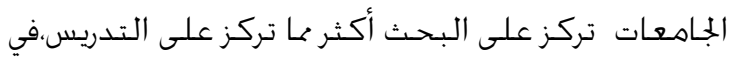

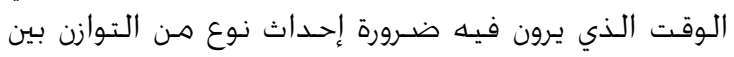

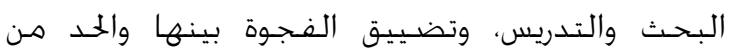

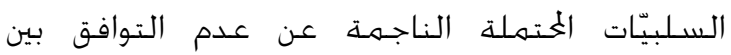

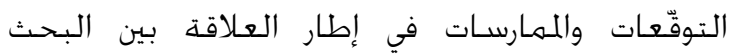

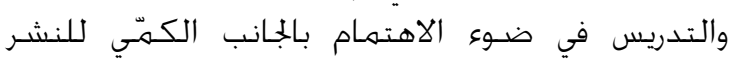

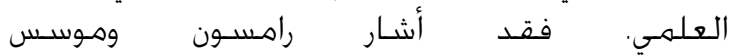
(Ramsden \& moses, 1992)

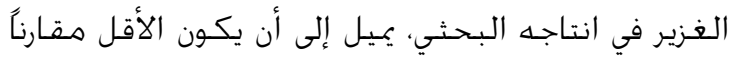

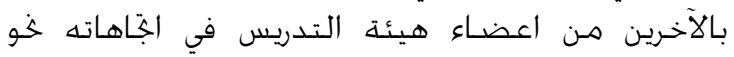

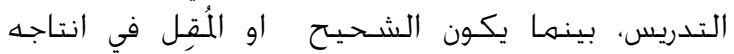

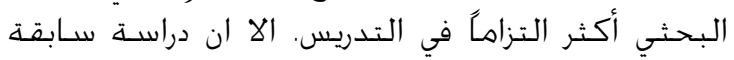

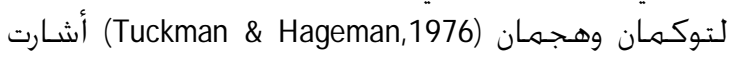

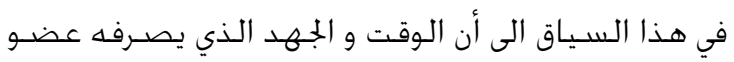

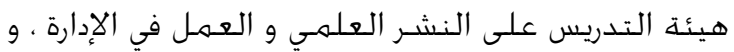

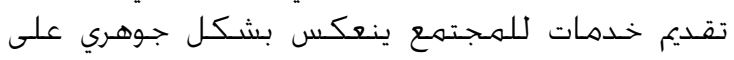

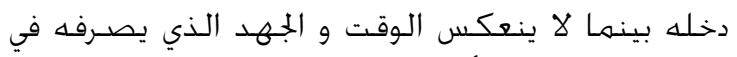
التدريس على دخله أو راتبه.

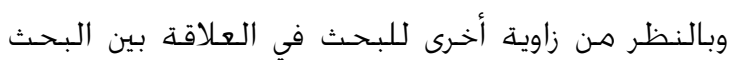

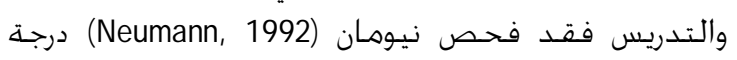

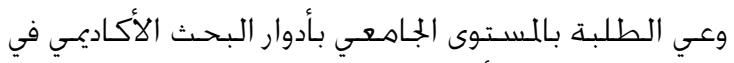

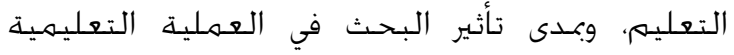

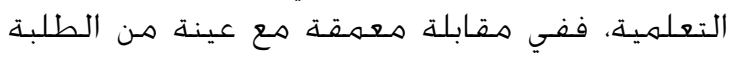

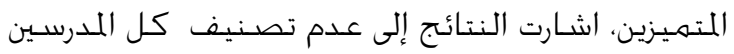

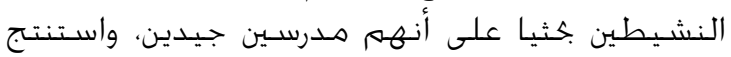

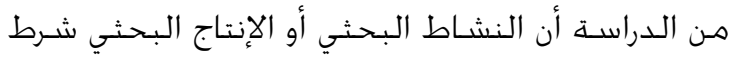

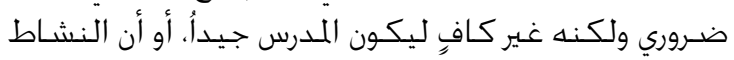

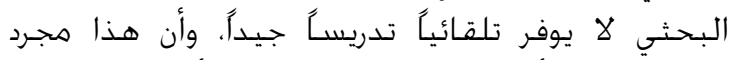

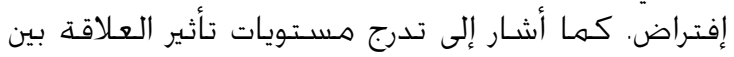

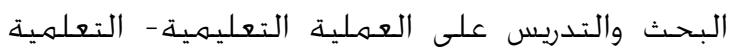

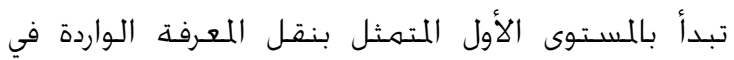

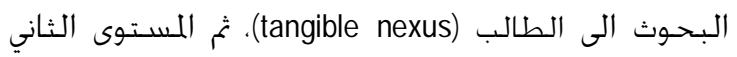
الذي يصبح فيه الطالب اندماجي (intangible nexus)

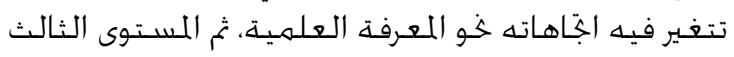

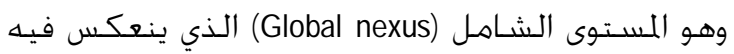

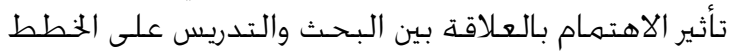
والـبرامج ومحتوى المساقات.

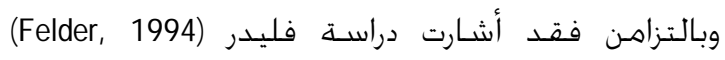

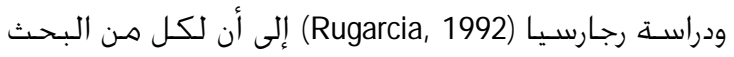

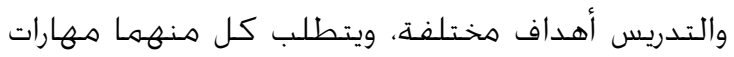

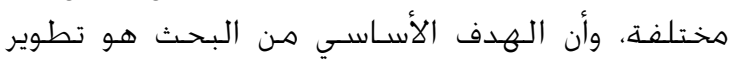
اللعرفة، بينما يهدف التدريس إلى تطوير وتعزيز قدرات الاست نطوير 
الدراسـات اللاحقة الى ان التفسيرات التي تمّ تقديمها في

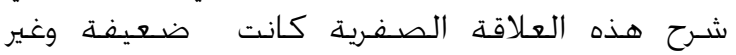

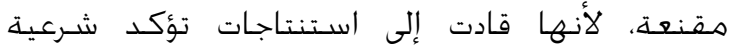

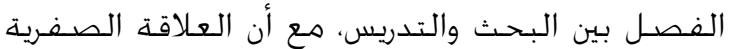

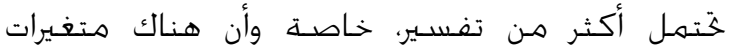
intervening or moderator or confounding وسيطة خدمة (Johnson \& Christen, 2004) variables

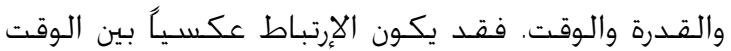

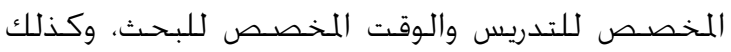

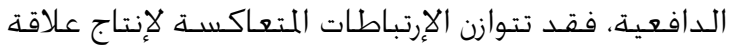

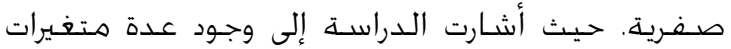

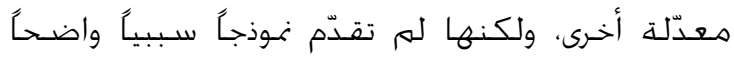

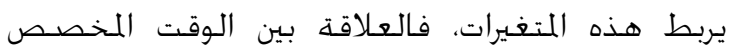

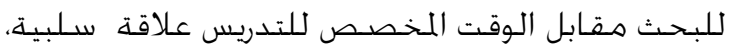

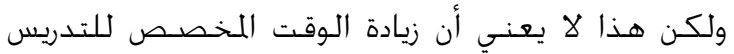

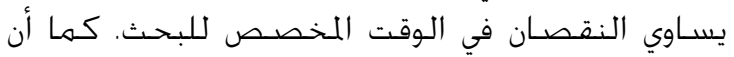

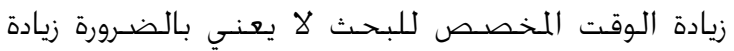

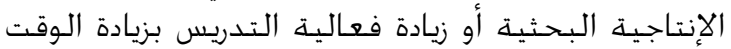

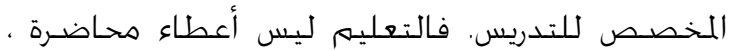

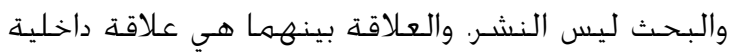

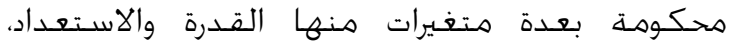

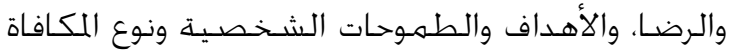

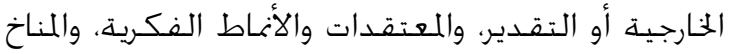

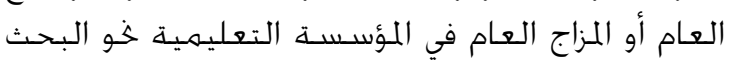

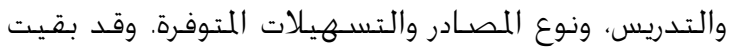

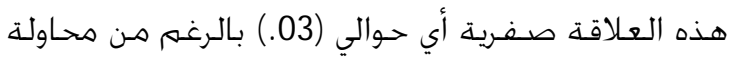

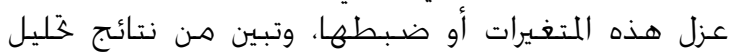

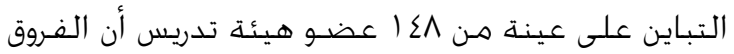

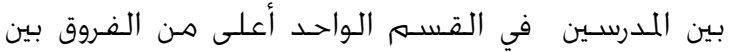

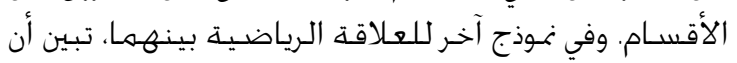

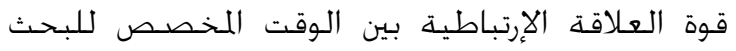

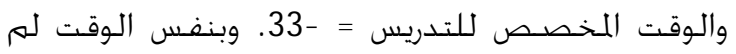
تكن العلاقة صفرية بين نواتج البحث ونواتج التهن التدريس.

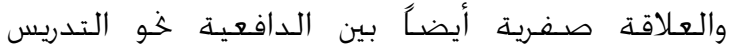
والدافعية خو البحث، أما العلاقة بين التقديرات الذاتية التهاتية

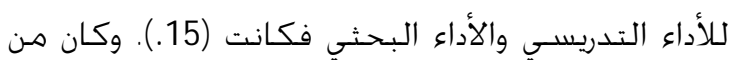

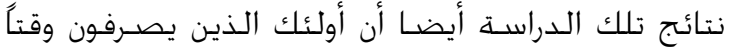

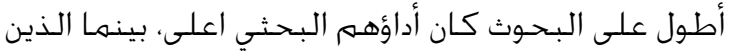

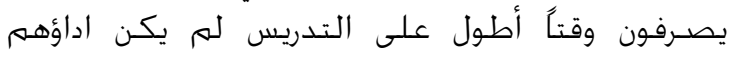

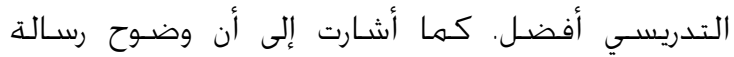
الجامعه وشيوع ثقافة البحث العلمي (Research culture)

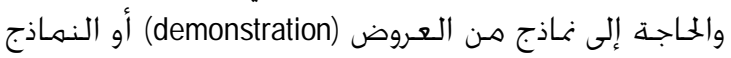

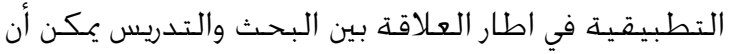

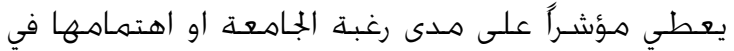

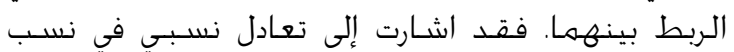

عضو هيئة التدريس في الربط بين البحث التدريس

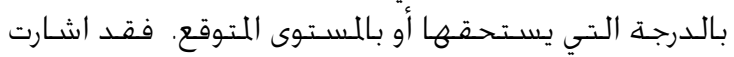
كريستينا (Cristina, 2002) إلى أن من مقاييس التميّز كمها

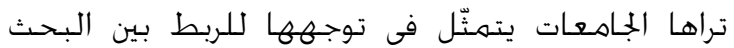

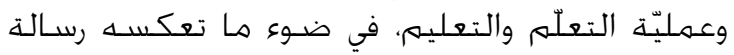

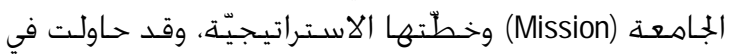

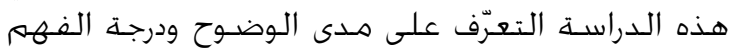

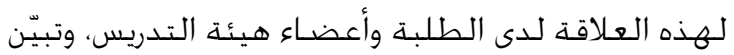

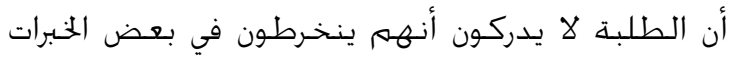

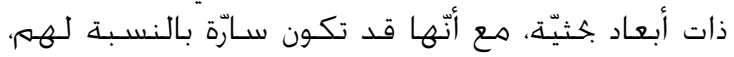

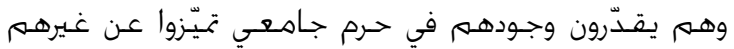

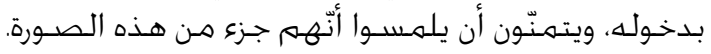
قابل التفاؤل في بعض الدراسـات المتهثل بمحاولةايجاد

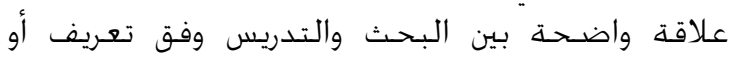

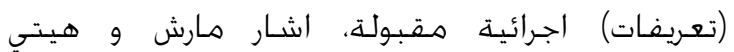
(Marsh \& Hattie, 2002)

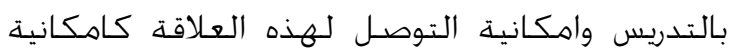

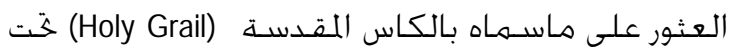

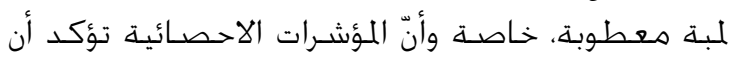

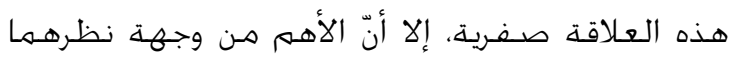

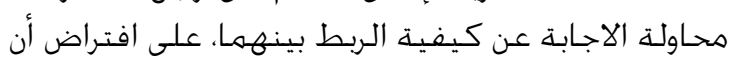

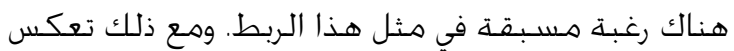

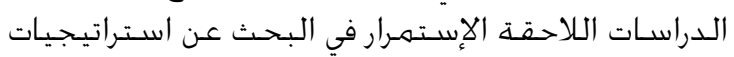

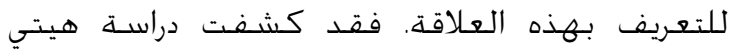
ومارش (Hattie \& marsh, 2004) المسحية والتتبعة

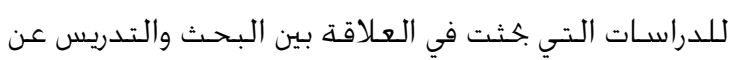

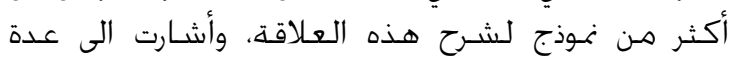

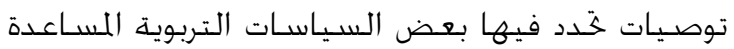
في توجيه هذه العلاقة وتفعيلها. ففي هذات التها الإطار؛

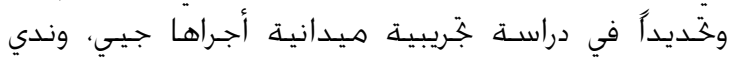

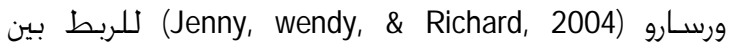

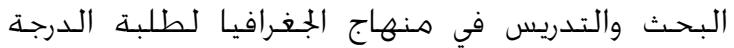

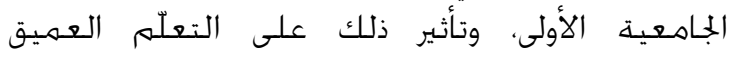

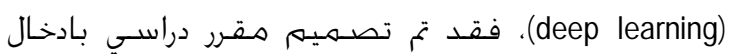

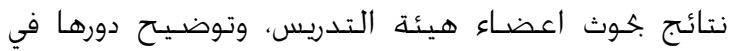

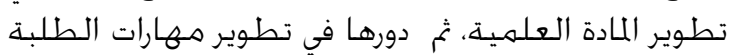

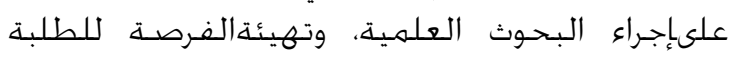

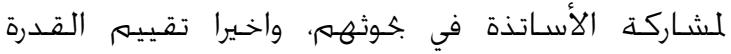

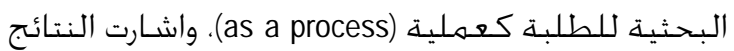

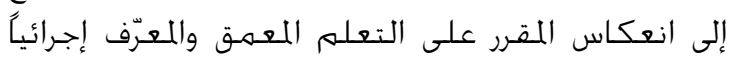
باكتسابهم للمهارات العقلية العليا مثل التحليل التهريل والتقوم للمعلومات.

وهمن الملاحظ أن نتائج هذه الدراسـات تعيدناإلى الدراسـات التحات

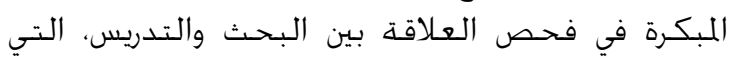

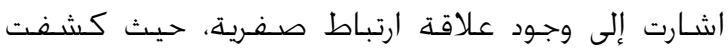




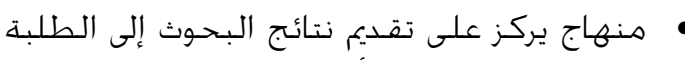

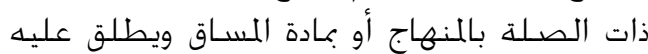

المنهاج اللقاد بالبحـث (Research- Led).

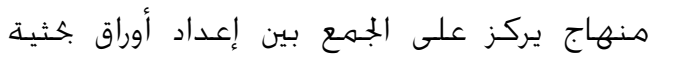

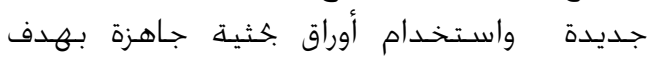

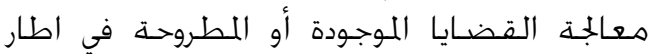

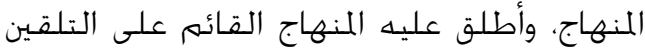
(Research- tutored)

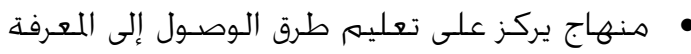

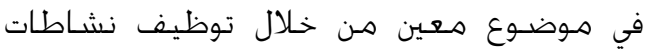

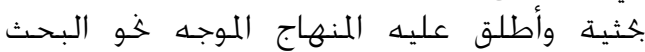
(Research- oriented)

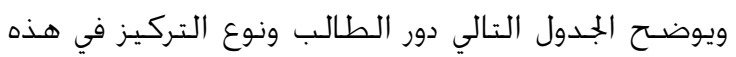
النماذج على متصـل المدخلين.

جدول النمال

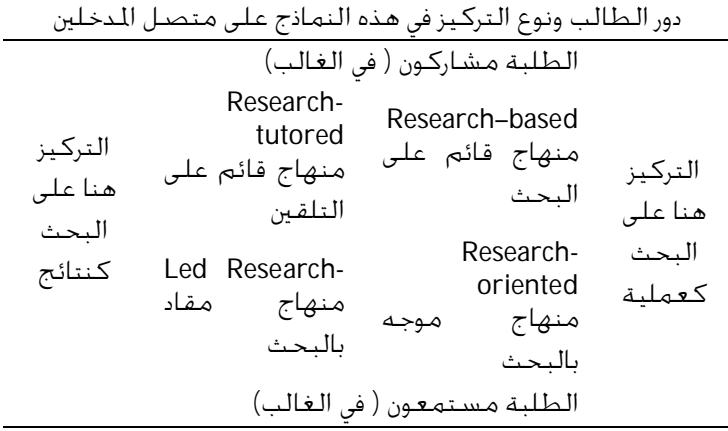

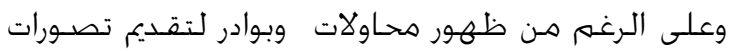

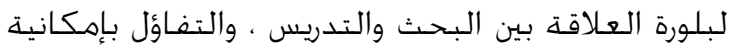

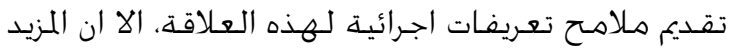

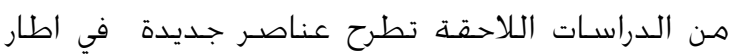

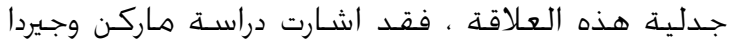

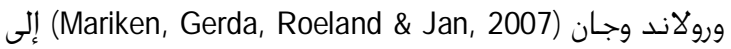

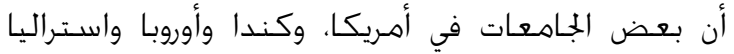

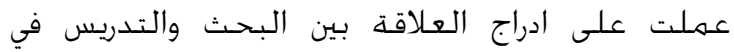
الخطط والمناهج الدراسية ومحتوى المسـاقات ضـمـن سياسـاتها التعليمية ورسالة الجامعة (mission)، وتشيري

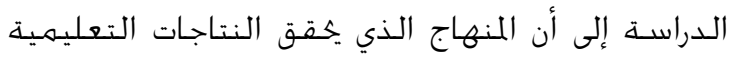

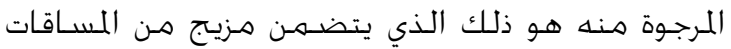

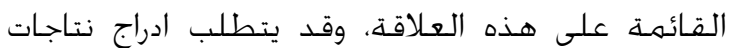

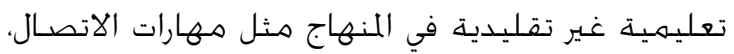

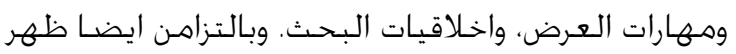

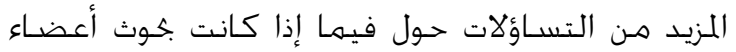

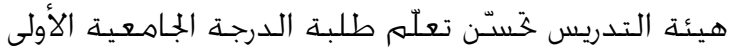

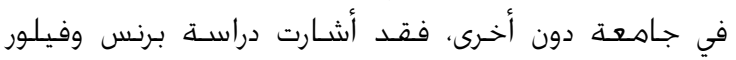

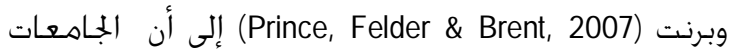

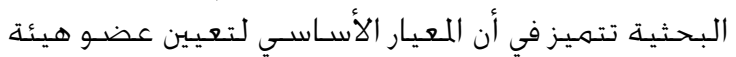

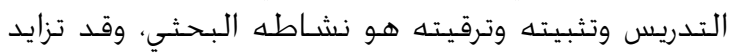

الفئات التالية هن أعضـاء هيئة التدريس في الجاهعات

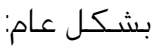

$$
\begin{aligned}
& \text { - فئنة بمسـتوى جيـد في البـحث التدريس. }
\end{aligned}
$$

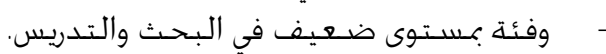

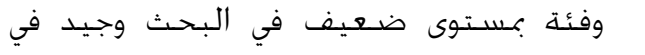

$$
\begin{aligned}
& \text { التدريس، } \\
& \text { - وفئة بمستوى جيد في التدريس وضـعيف في } \\
& \text { البـحـث. }
\end{aligned}
$$

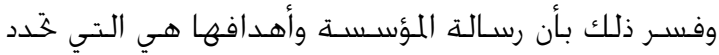

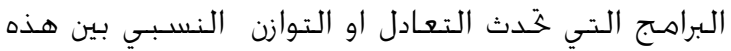

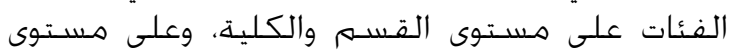

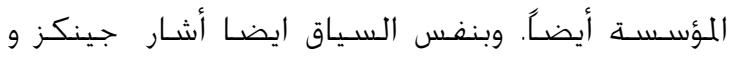
هيلي (Jenkins \& Healy, 2007 ) الى أن العلاقة بين

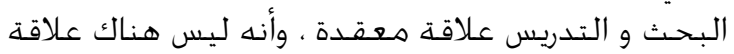

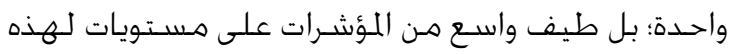

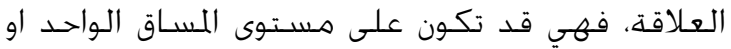

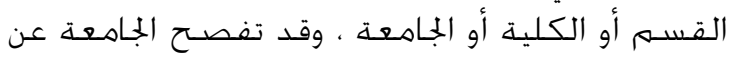

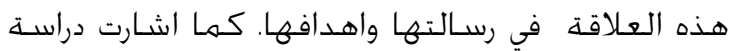

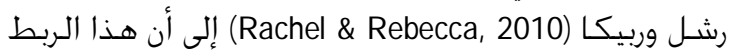

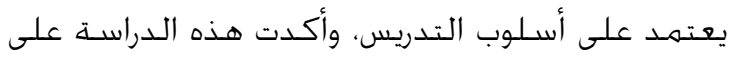

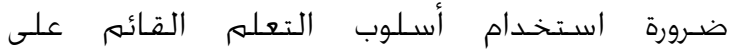

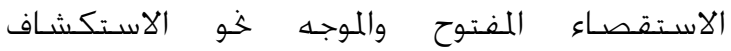
كاستراتيجيـة للربط بين البحـث والتـدريس. وكانت نتائج

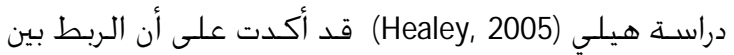
البحـث والتـريس في التخصـصـات الطبية كان تأثيره

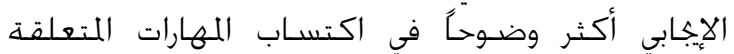

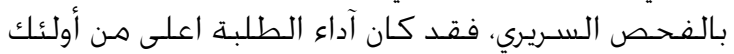

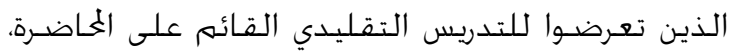

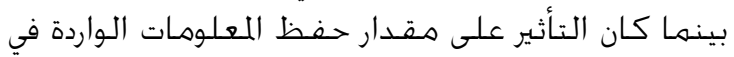

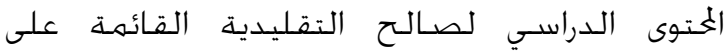

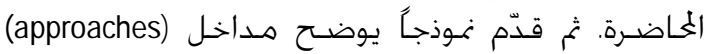

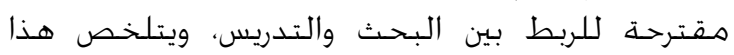

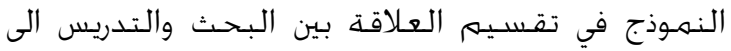

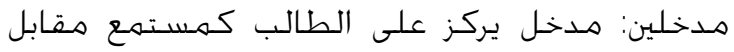

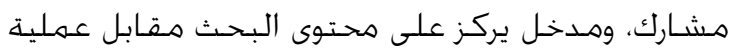

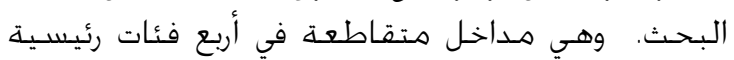

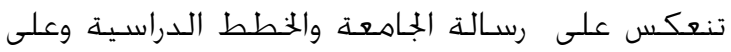

$$
\text { محتوى المسـاق الواحسـ على النـحو الآتي: }
$$

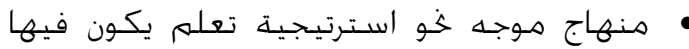

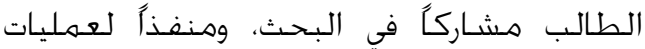

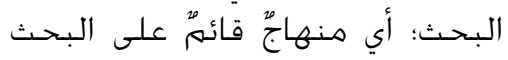

يكون فيه الطالب مســعداً (Research -based)

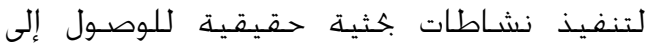

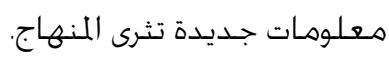


بين البحث والتدريس بدعم من صندوق دعم التعليم

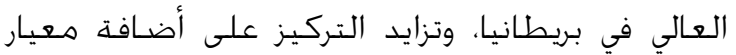

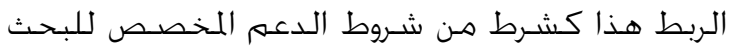

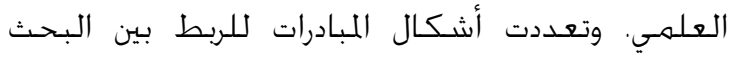

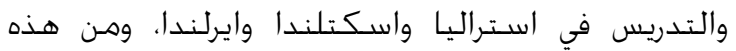

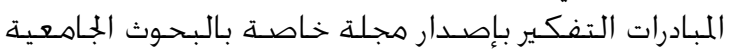
للطلبة (Undergraduate research journal)، وربط البحث البحث

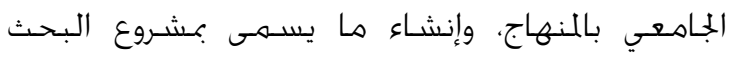

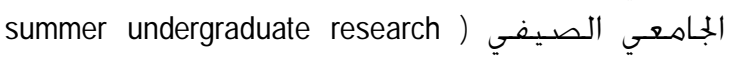
(projects ثومبسـون(Lysaker \& Thompson, 2013) الى جُربة لهـما

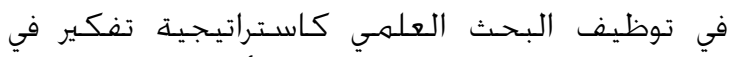

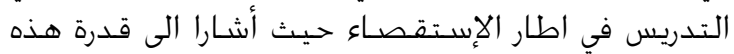

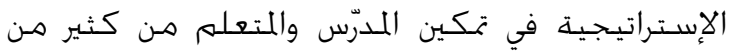

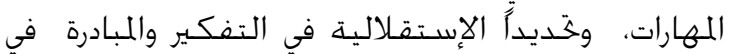

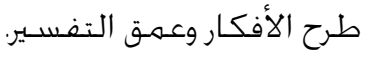

وفي الوقت الذي تتناول فيه الدراسات واقع البحث والتدرس والربط بينهما في الجامعات بأنواعها وبرامجها ومواقعها، وعلاقة ذلك بفلسفة في الجامعات الجامعة وأهدافها ورامها

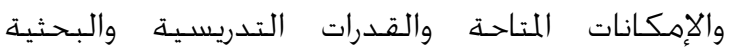

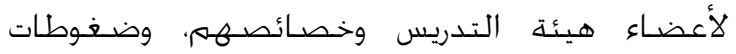

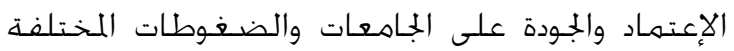

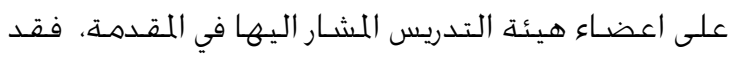

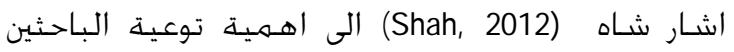

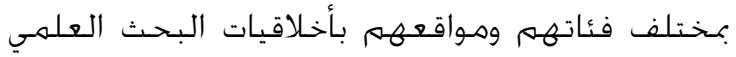
والسـرقات العلمية ومخاطرها المنظورة وغير المنظورة. وقد الندي أشـارت إلى خطورة (Jenkins, 2000; Hattie \& Marsh, 1996) الإلتزام بقاعدة النشـر او الطرد

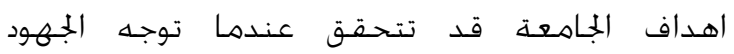

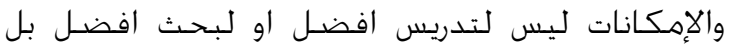

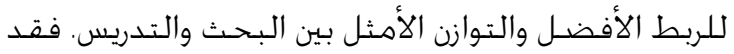

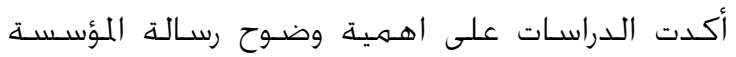

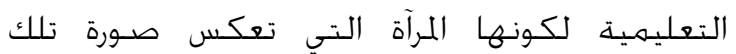

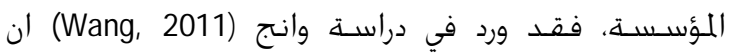

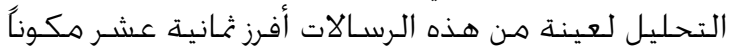

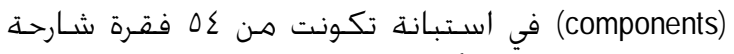

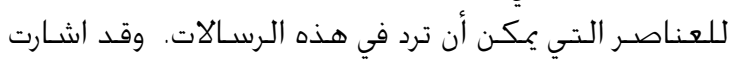

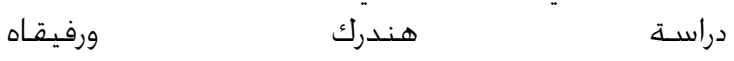
(Hendrik, van Dalen \& Henkens, 2012)

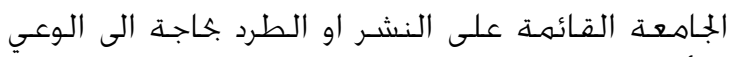

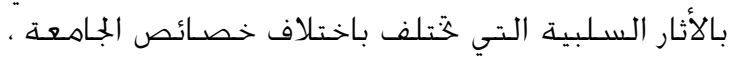

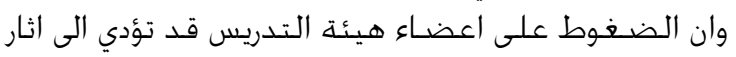

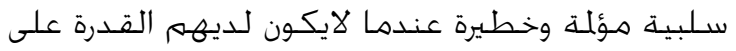

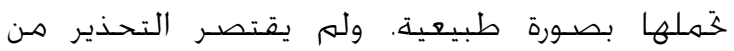

الاهتمام بهذا المعيار مع تنامي اعتماد الجامعة في

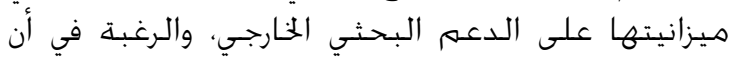

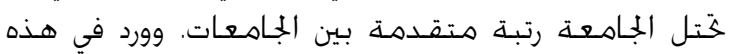

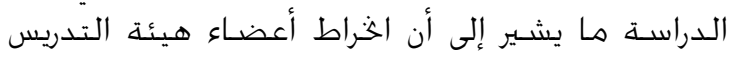

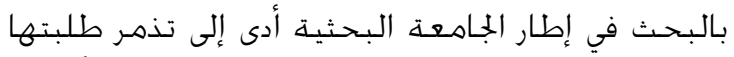

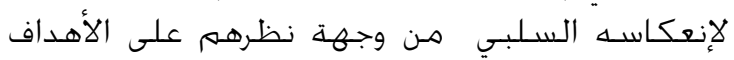

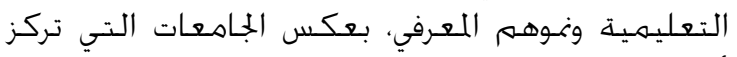

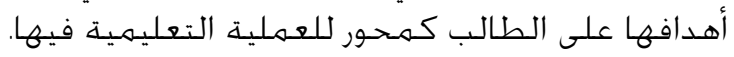

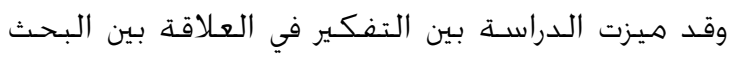

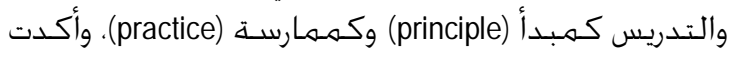

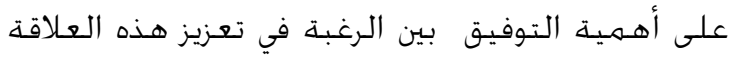

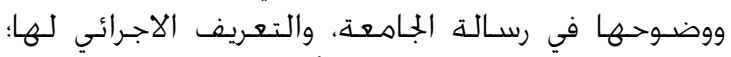

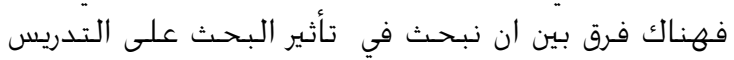

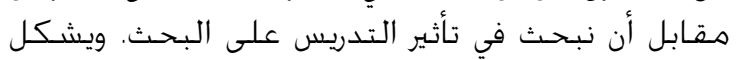

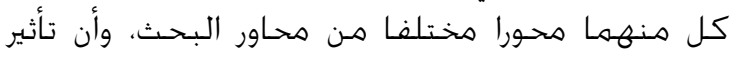

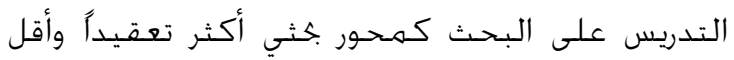

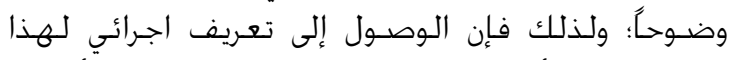

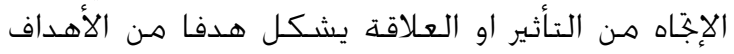

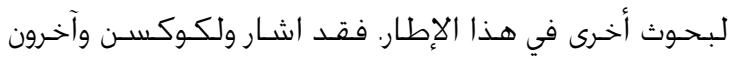
إلى (Willcoxson, Manning, Johnston \& Gething, 2011)

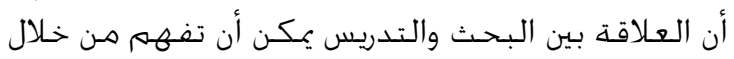

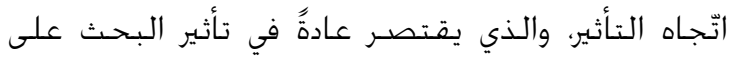

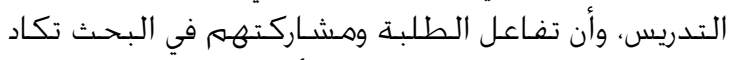

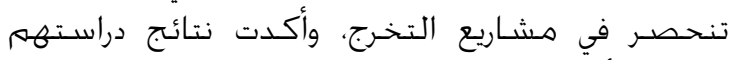

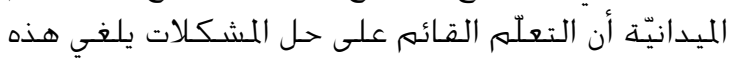

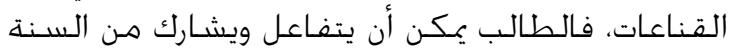

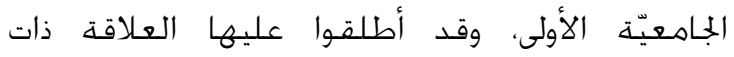

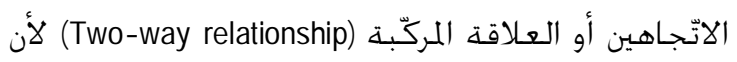

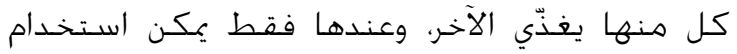

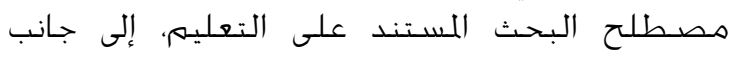

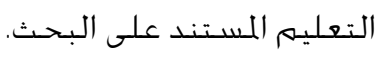

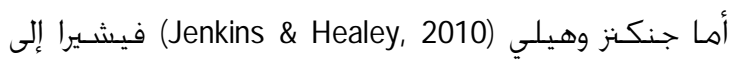

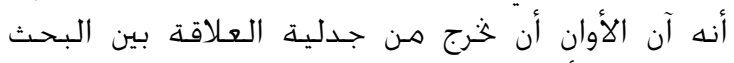

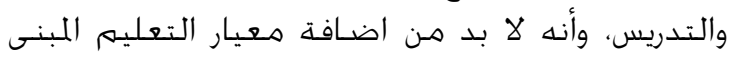

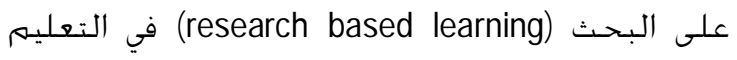
الجامعي، وتداول استخـدام مصطيلح البحث الجامعي. (undergraduate research)

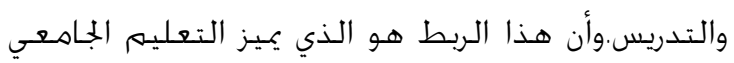

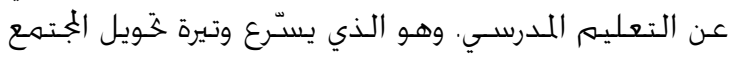

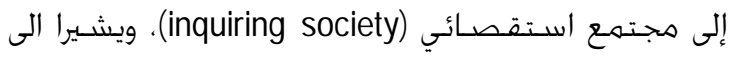

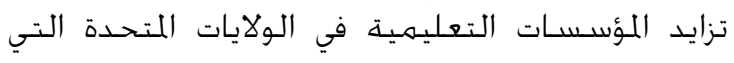

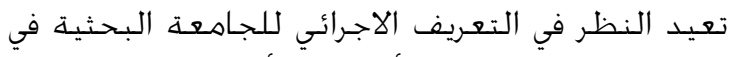

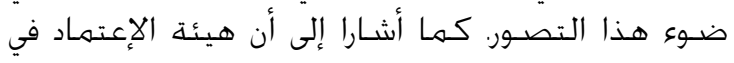

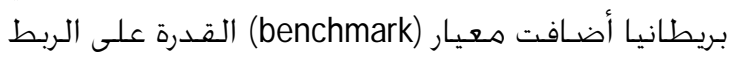
بين البحث والتدريس. وانشـاء مـراكز تميز قائمة على الرة الربط الريط 


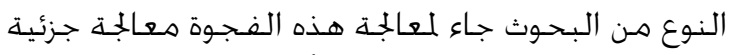

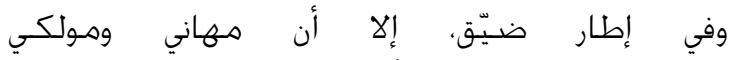
(Mahani \& Molki, 2012)

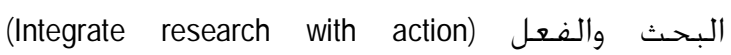

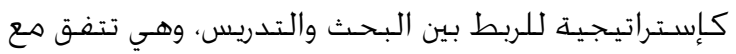

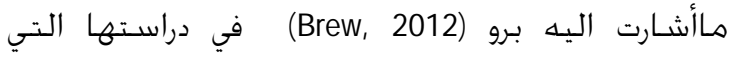

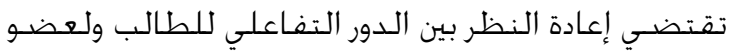

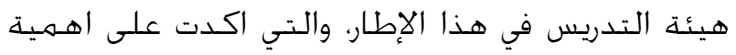
اعادة النظر في التصـور المفاهيهي (re-conceptualize)

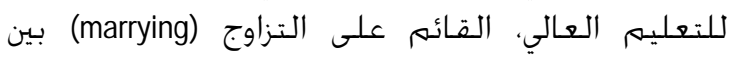

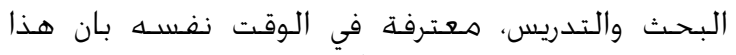

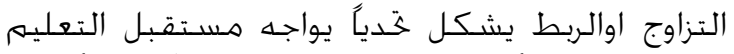

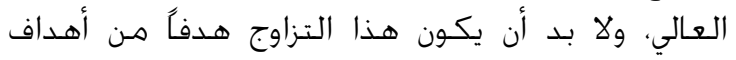

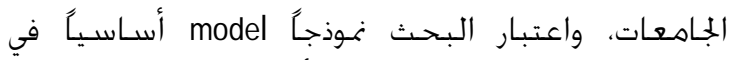

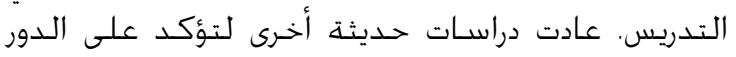

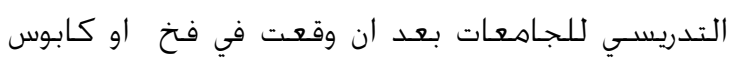

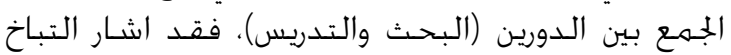
(إلى ما يلي: (Altbach, 2012)

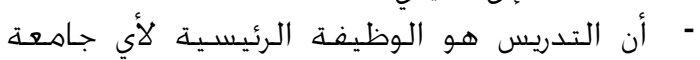

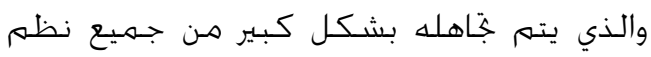
largely ignored in all of ) الترتيب للجاهعات

.)(rankings

أن بعض نظم الترتيب مثل التايمز (E) Times Higher (Education Ranking صلة أكبر بالتـديس وبوزن أكبر، مقـابل الوزن الأكبر

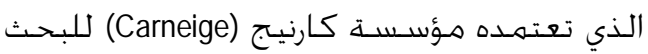

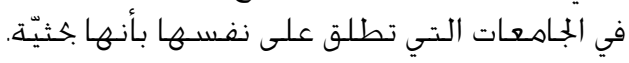

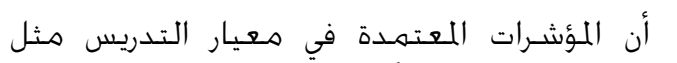

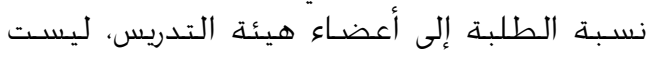
في جـوهر نوعيّة أو جودة التدريس (Teaching Quality).

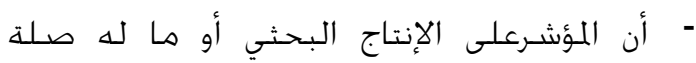

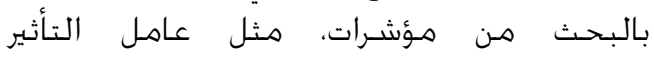

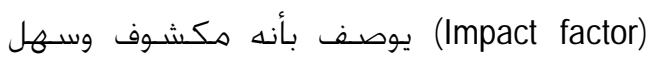

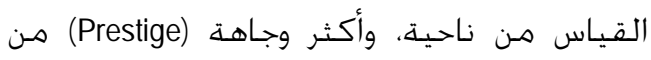

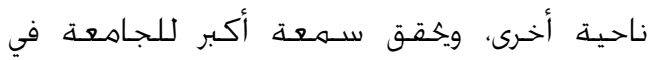
الشـكل لافي المضـمـون.

- أن بعض الجامعات وخـاصـة في بعض الدول

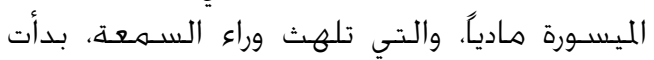

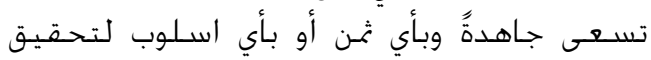

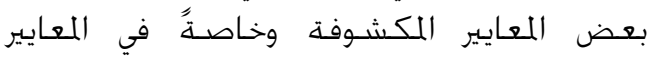
القـائمــة على البحـث العلهـي.

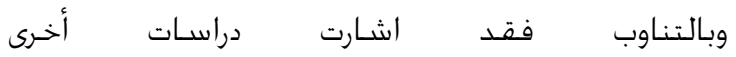
(Singh, Reid, Bown, Mager \& Santoro, 2013) تعزيز العـلاقة بين البحـث والتدريس مـن خـلال البراهج التي التي
التطبيق الأعمىى لشعهار النشـر اوالطرد او للثقافة

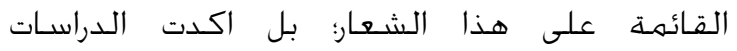

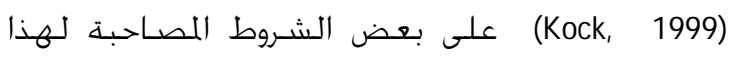

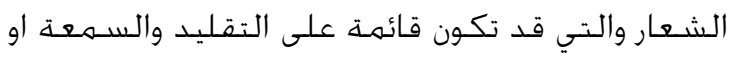

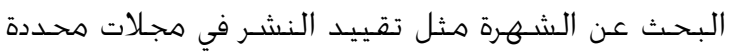

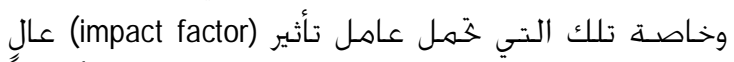
واحتهالات انعكاس ذلك على اخـلاقيات البحـث. وأشـارت

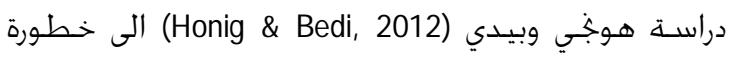

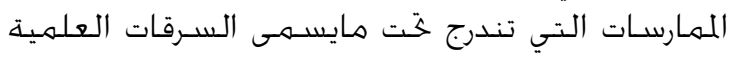

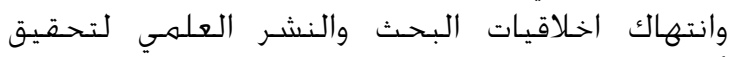

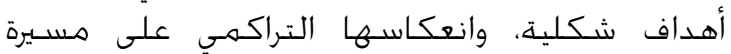

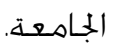

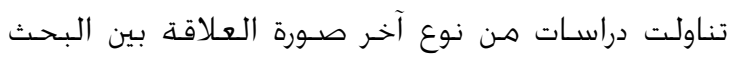

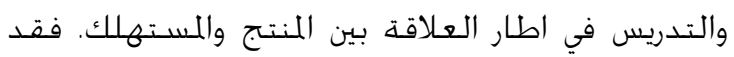

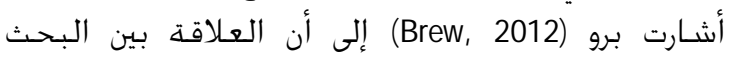

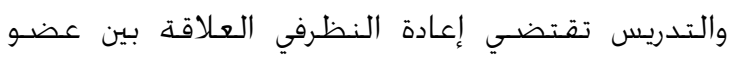
هيئة التدريس والطالب وبعض المستمارسـات التي تميز بين

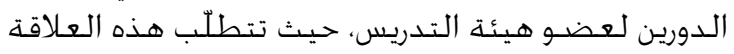

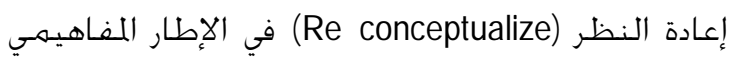

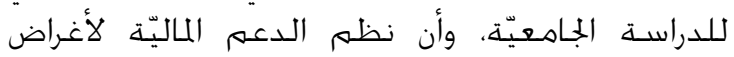

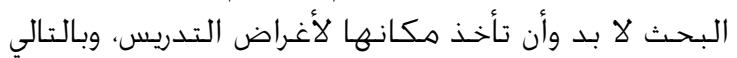

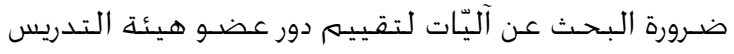
في الربط بين البحثث والتـريس، في إطار الخطّة الدراسيّيّة (Undergraduate curriculum)

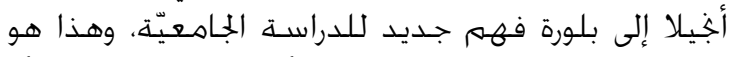

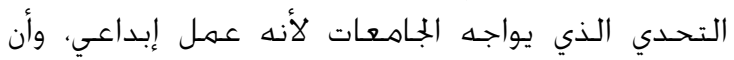

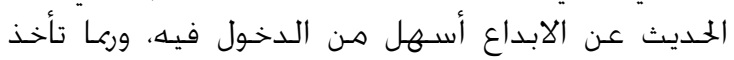

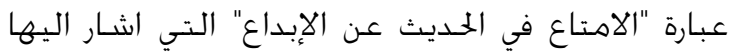

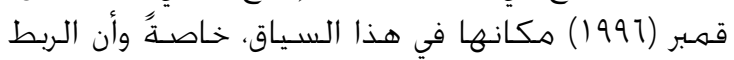

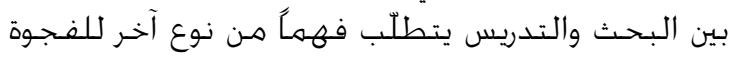

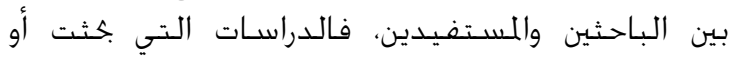

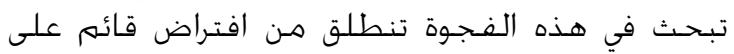

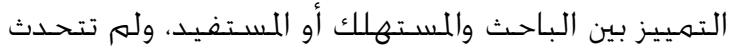

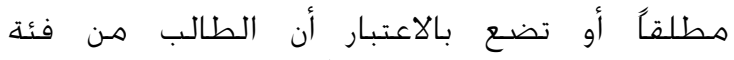

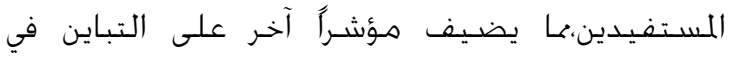

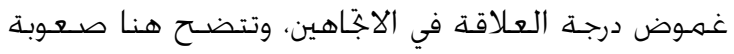

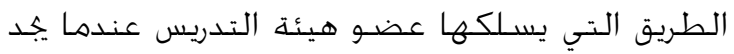

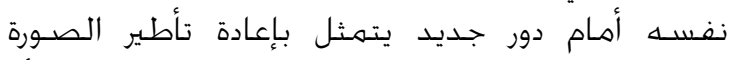

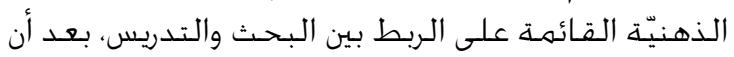

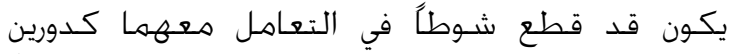

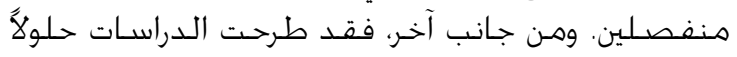

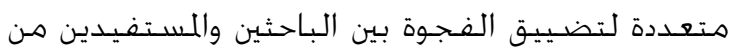

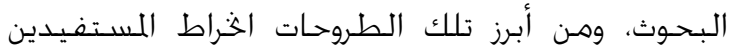

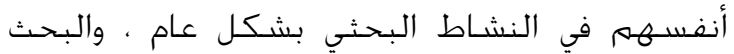

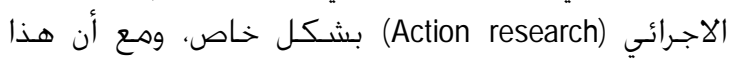


ومتطلبات هيئات الإعتماد الدولية في إطار العولة.

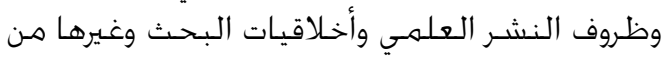

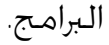

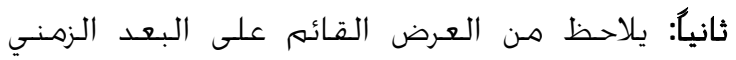

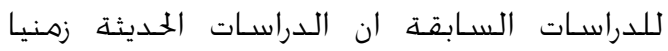

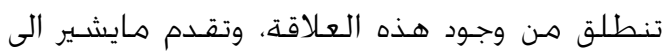

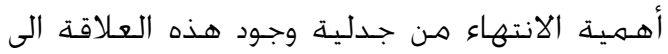

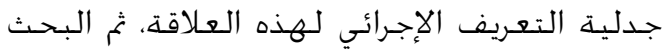

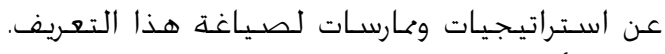

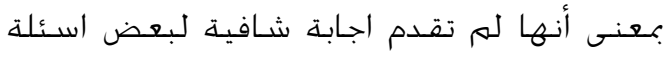

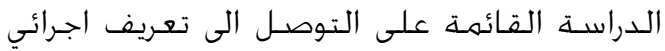

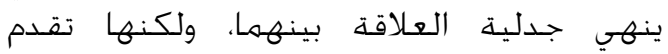
معلومات مساعدة في بلورة عدة تعريفات اجرائية،

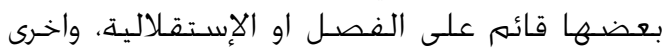

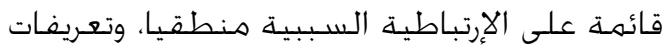

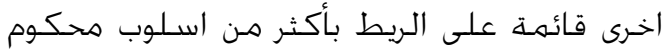

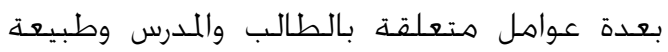
المسـاق وظروف المؤســــة.

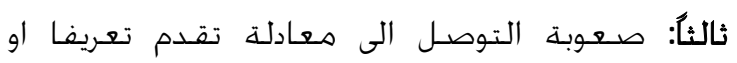

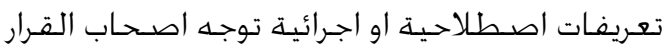
في الجامعات وأعضاء هيئة التدريس وكل التورئ المتاثرين

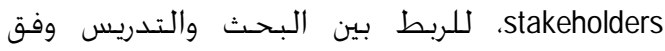
فلسفة ورؤية واضحة، ويمكن توضيح ذلك الك من خلال

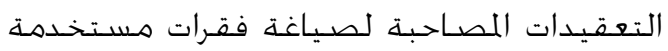

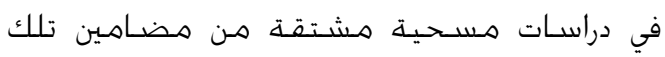

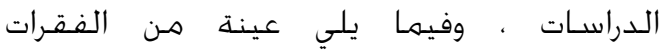

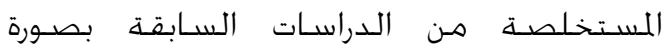

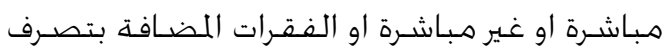

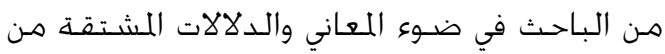

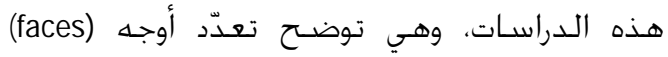

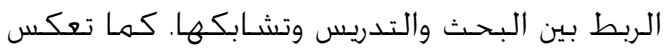

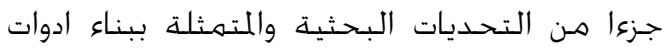

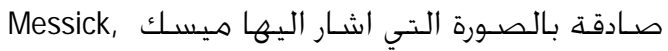

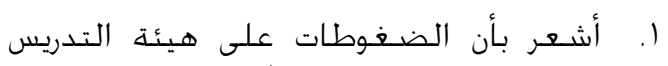
لإجراء بكوث تنعكس سـلبياً على التدريس.

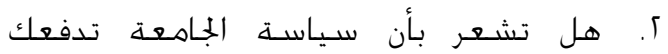
لتخصيص وقتاً أطول للبحث على حساب الجـامع تدفاب

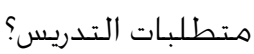
r. الإنتاج البحثي هو الذي يحدد سـمعة الجامعة وليس التدريس. ع. أشعر أن التوفيق بين متطلبات التدريس ومتطلبات البحث يشكل هاجساً كبيرًا لدى الند أعضـاء هيئة التدريس.
تقوم على تأهيل المدرسين، وتوظيف البحث في تطوير

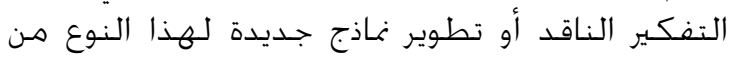

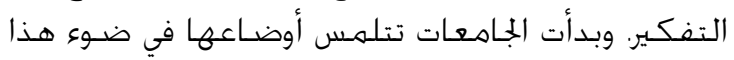

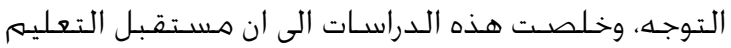

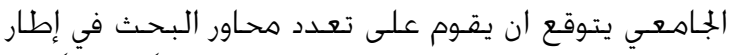

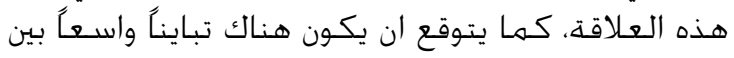

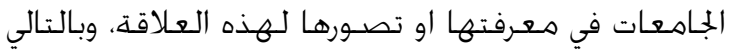

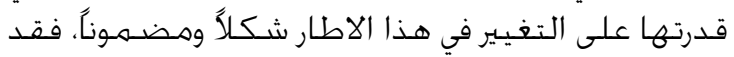

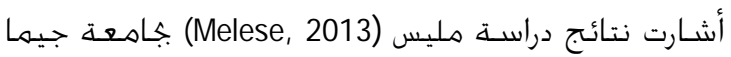

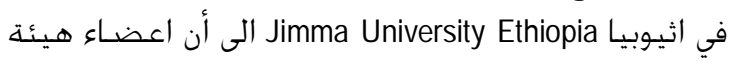

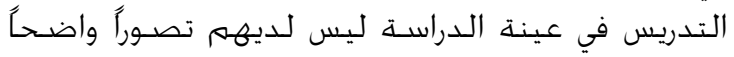

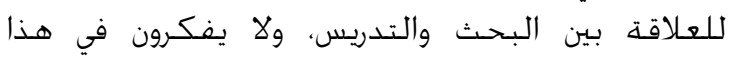

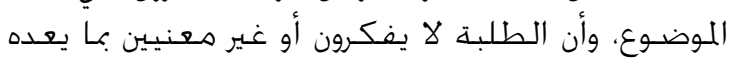

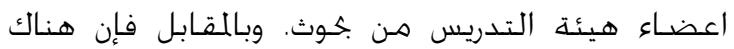

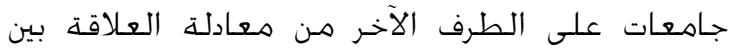

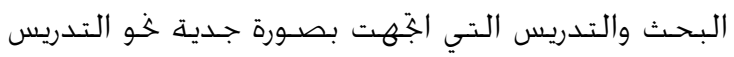

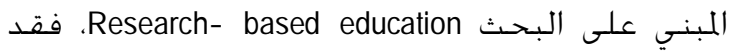

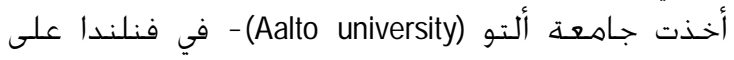

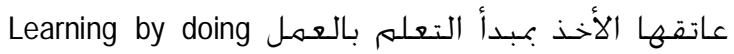

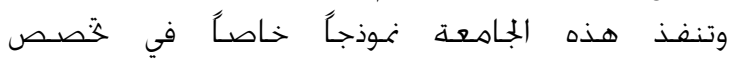

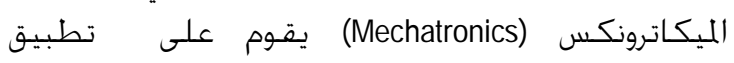

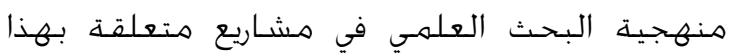

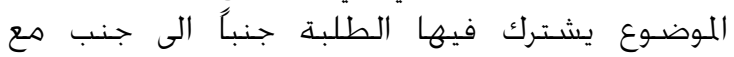

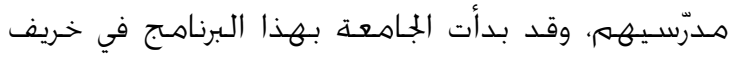

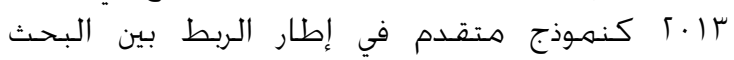

والتدريس.

النتائج والمعاني المشتقة من الدراسـات السابقه

يتضـح من القـراءة المتأنية للدراسـات السـابقة مايلي:

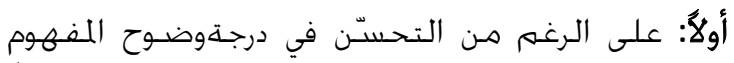

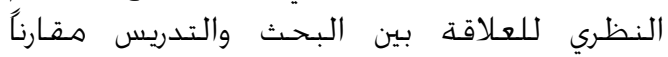

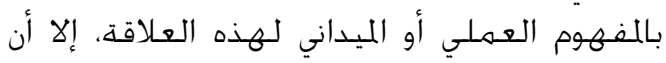

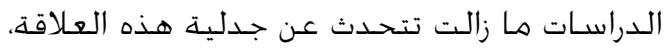

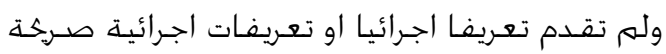

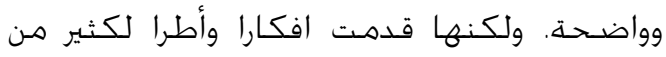

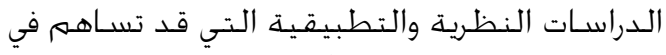

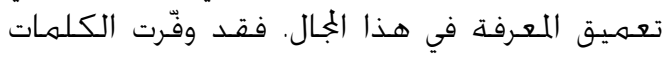
المفتاحية keywords التي تسهـل فئل دخول الباحثين

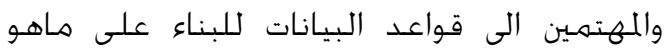

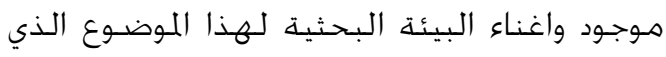

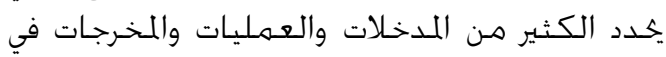

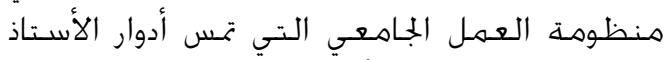

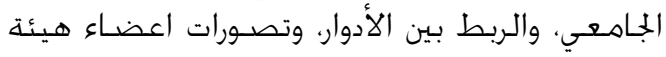

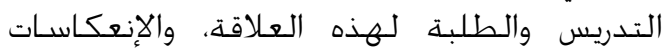

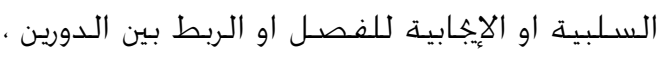
وعلاقتها كذلك بمتطلبات الإعتماد والجادودة. 


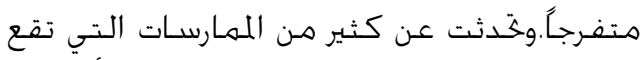

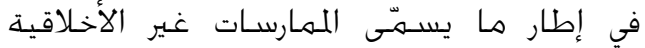
والسـرقات العلميّيّة (Dishonesty or misconduct) وشَّع ذ ذلك على تطوير برامج (plagiarism) محوسبة (software) للكشف دـف عن هذه السـرقات

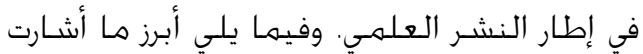

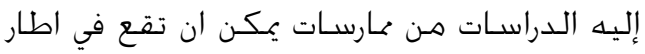

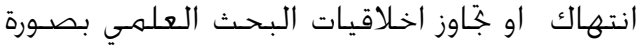

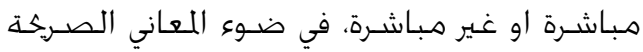

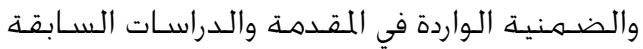

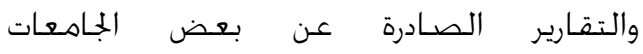
(Marcia (1997), Bird (2002), University of Minnesota Center for Bioethics (2003), Maureen Dawson. \& Overfield :(2006), Mason (2009),

.Young (2001) ا. . إعـادة صـياغة عنـوان بحث بمفـردات أخـرى. ז. توجيه نتائج بحث لخدمة أغراض معيّنة (فبركة النتائه).

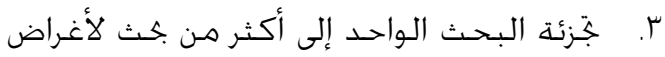
كميّة (عدد البحوث).

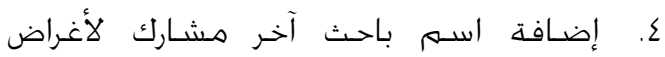
التنفيع (هـن باب الصـــاقة أو المعـرفة). 0. تبادل المنفعـة في تدوير أسسماء نفس الباحثين على أكثر مـن بحث دون مشـاركـة فعليّة. 1. تبادل المنفعة بين الباحثين في خديد موقع الباحثث الرئيسـي.

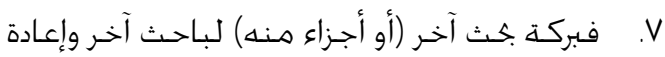
نشـره. ^. عـدم التوثيق العلومات هـن رسـالة أو أطروحـة أشـرف عليها. 9. الطلب هـن الطالب التنازل عن حقــ في المشاركة بالنشـر.

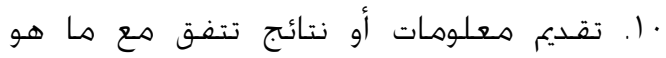

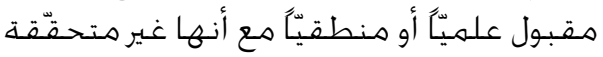
فعلاً. ا ا. ادّعاء الباحث أنه قام ببعض الاجراءات مع أنّه فبركها.

؟1. التجـريب على أفراد غير هدركين لخجهم الضـرر الذي يلحق بهـم هـن مشـاركتهـم في التجرية. \% ا. اختيار التوقيت لجمهع المعلومات مـن مصـادرها

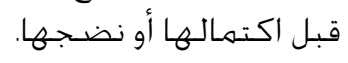

0. أعتقـــ أن على المدرّس في الجـامعة أن يكرّس

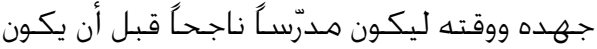
باحثًاً ناجهـاً.

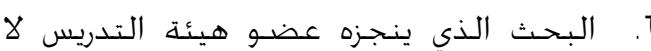

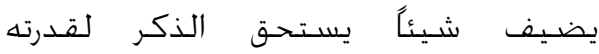

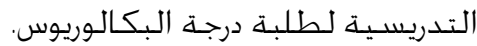

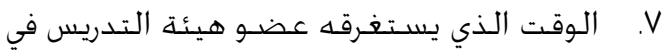

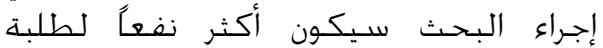

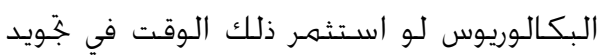
العـملية التـريسـية.

عضـو هيئة التـدريس الجيــ هو الذي يستخـدم

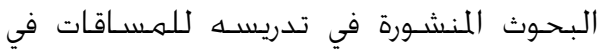
مرحلة البكالوريوس.

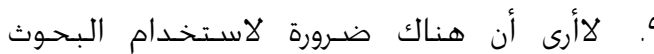

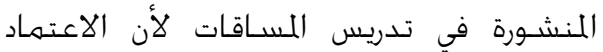

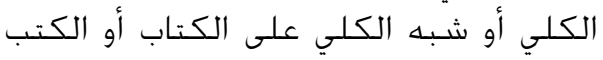
اللقـررة.

• (. تعليم الطالب مهارات التفكير ومهارات

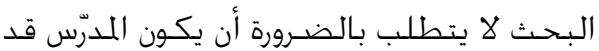
نشـر بحثًا. 11. التدريس يغذي البحثث والبحـث يغذي التدريس فالعلاقة بينهما متبادلة. ז ا. الباحثث الجيــ أكثر قدرة على نحليل محتوى المادة

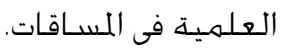

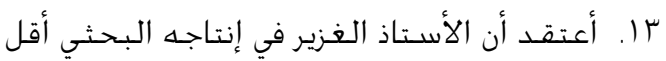

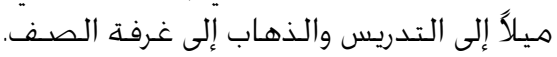

ع ا. اشعـر بأن للجامعة رسـالة واضحـة توازن بين البحـث والتـدريس.

ها. أرى أن التركيز على التدريس أكثر جـدوى هـن التركيز على البحـث النيز

رابعاً: تطرقت الأدبيات والـدراسـات السـابقة إلى جـملة هـن

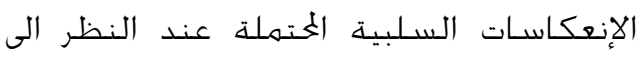

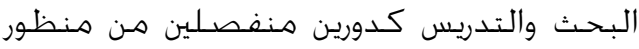

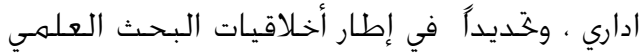

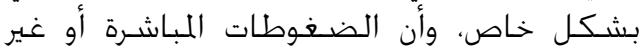

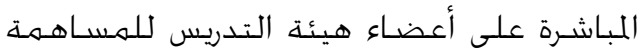

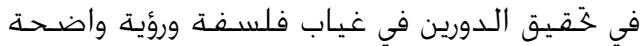

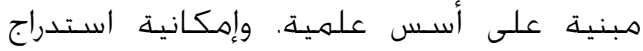

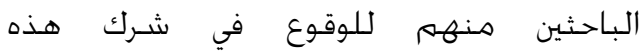

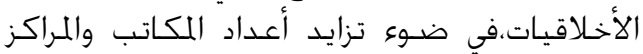

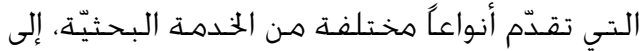

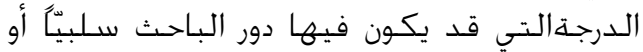


السـابقتين، وأن التحدي يكمهن في القدرة على

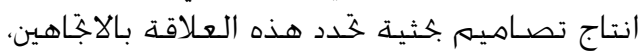

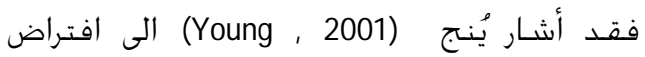

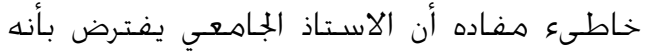

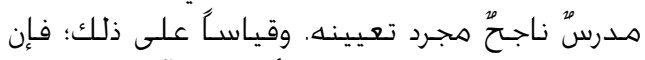

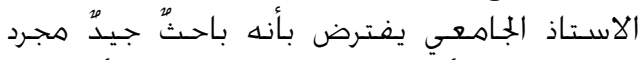
تعيينه. إلا أن المؤشرات ترجيح خطأ هذئ هذين الافتراضين.

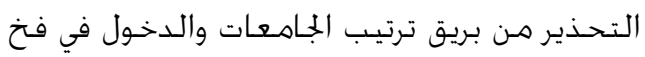
سباق من هذا النوع في اطار العولمة، والإهتمام ترني بقيمته الظاهرية على حساب توازن المؤسسـة الاهنة

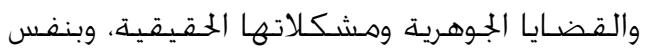

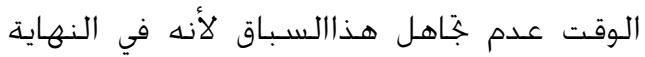

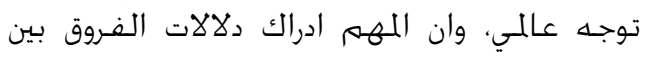

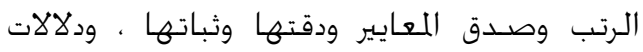
اختلاف هذه الععايير من نظام الى آخر. سادساً: خدثثت الأدبيات في المقدمة والدراسـات السـابقة

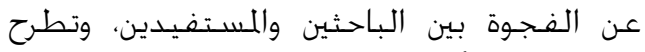
بعض الحلول أو الاقتراحات لتضييق وليق هذه الفجوة.

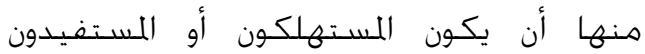

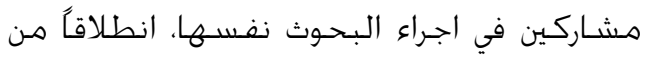

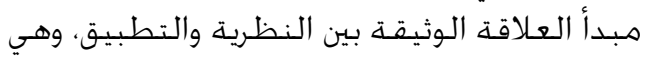

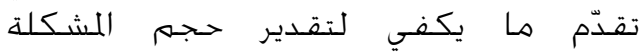

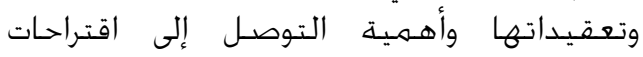

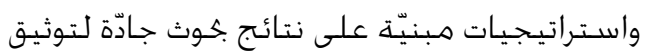

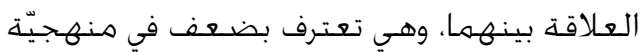

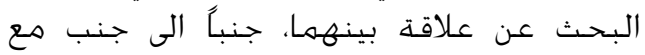

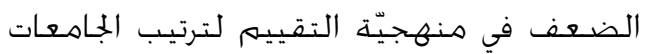
وتصنيفها حتِّى في التعامل مع البحث والتدريس التهن كدورين منفصلين، ويرى الباحث أهميّة إضـافة التهائ

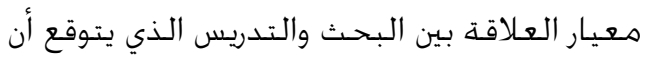

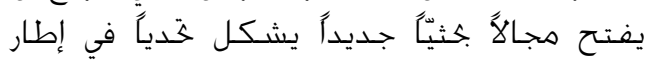

$$
\text { منهجيّة التقييم هذه. }
$$

سابعاً: ميّزت الدراسـات السابقة بين دور عضو هيئة التدريس كمستكشفٍ أو كمستقصٍٍ (searcher) ودوره كباحث (researcher)عند التفكير في الربط التهات

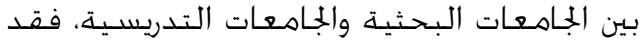

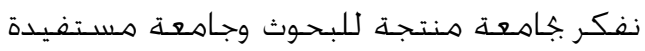

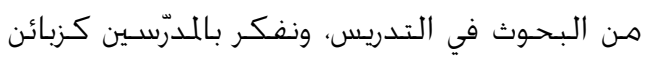
(stakeholders as consumers)

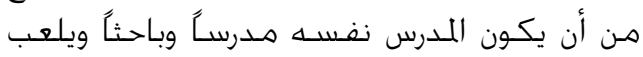

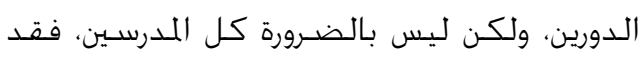

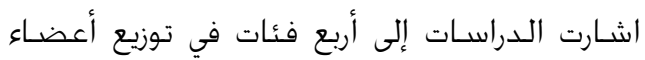

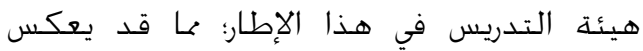
اختلافًاً جوهرياً في شئروط الترقية والتثبيت والنقل
خامساً: اعتمد الباحثون في العلاقة بين البحث والتدريس

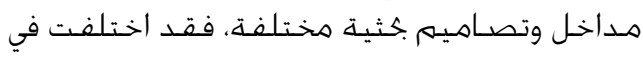

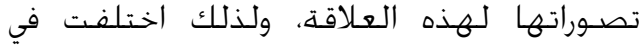

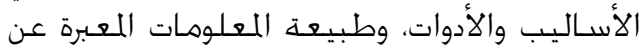

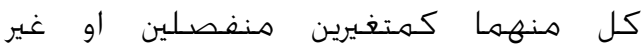

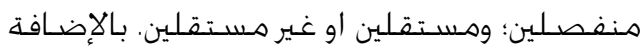

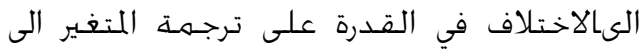

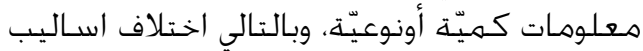

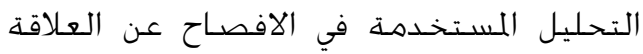

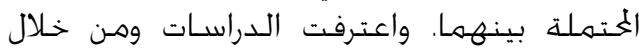

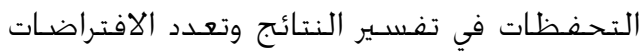
التي انطلقت منها تصاميه تلك تلك الدراسـات

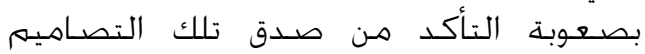
وموثوقية النتائج التي توصلت اليها، وفيما يلي لئي عرض لأبرز مداخل البحـث في هذا الموضـوع:

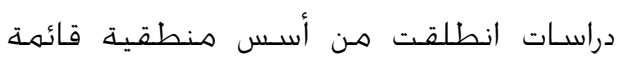
على شـروط تعيين الاسـاتذة في الجامعات.

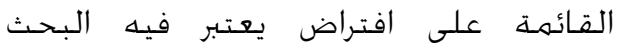

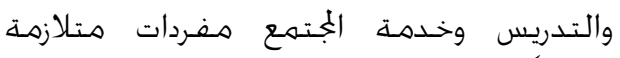
تلقائيًاً.

تزايد شيوع ع عبارة النشـر أو الطرد مع تزايد الضغوط على Publish or Perish الجامعات التي تطلب الاعتماد للبرامسج في اطار

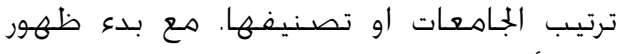

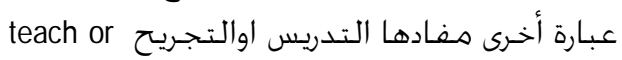
impeach على الرغه هن أن الدراسـات التي بحثت في

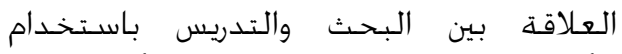

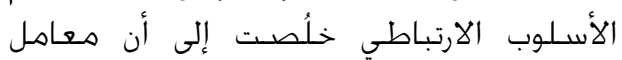
الارتباط بين الانتاج البحثي وتقييم الإني الاداء التدريسي لا يختلف عن الصفر، وأنهما متغيرين منفصلين P(TUR)=P(T)+P(R) أي أن النيف T احيث P(TnR)=0

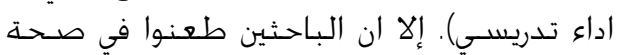

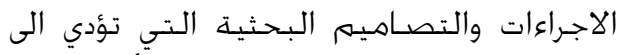

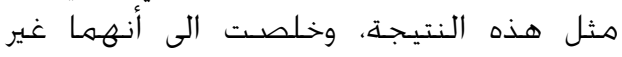

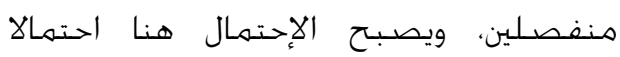

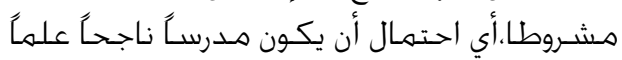
بأنه باحث ناجـا أو العكس.

$$
\begin{aligned}
& \mathrm{P}(\mathrm{T} / \mathrm{R})=\mathrm{P}(\mathrm{T} \cap \mathrm{R}) / \mathrm{P}(\mathrm{R}) \\
& \mathrm{P}(\mathrm{R} / \mathrm{T})=\mathrm{P}(\mathrm{R} \cap \mathrm{T}) / \mathrm{P}(\mathrm{T})
\end{aligned}
$$

بعد أن يكون الباحث قد حدد درجات قطع أنسات

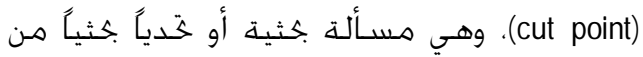

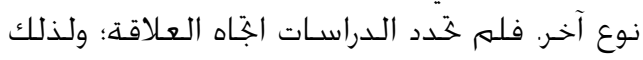
فإن هذه العلاقة ختمهل التعبير عنها بالمعادلتين التراني 


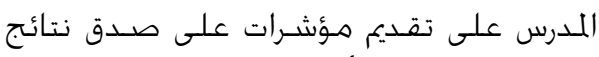

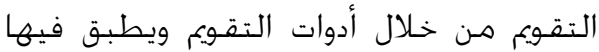
مفهوم التثليث Triangulation بأنواعه (عبر التخو

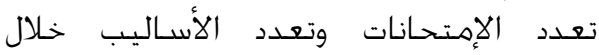
الفصـل الدراسي (methods and time over tests). • المطلوب من الباحث معرفة المتغيرات

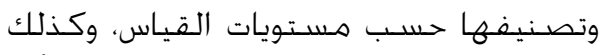

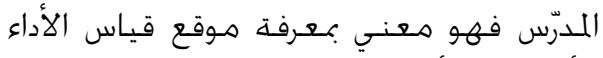

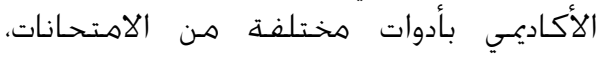
والمقابلات (Evaluation Rubrics) المختلفة الموضوعية منها والانشائية، وبالتالي

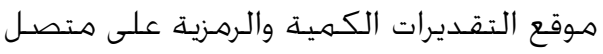

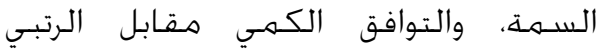

للدرجات.. (Rank isomorphism value vs)

ولذلك فإن إتقان عضو هيئة التدريس لمهارات البحث التهن

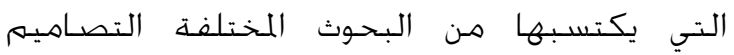
والمنهجيات تتقاطع مع مهارات التدريس او بعضهات المخها.

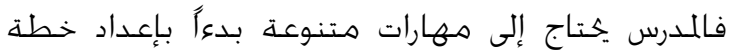

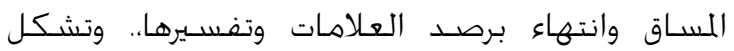

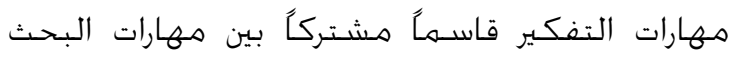

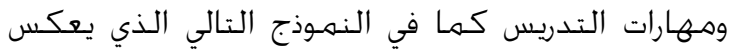

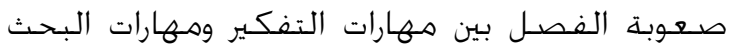

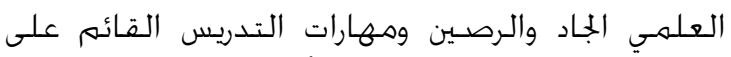
الإستقصساء والتعلم النشط للأسباب التي تليه:

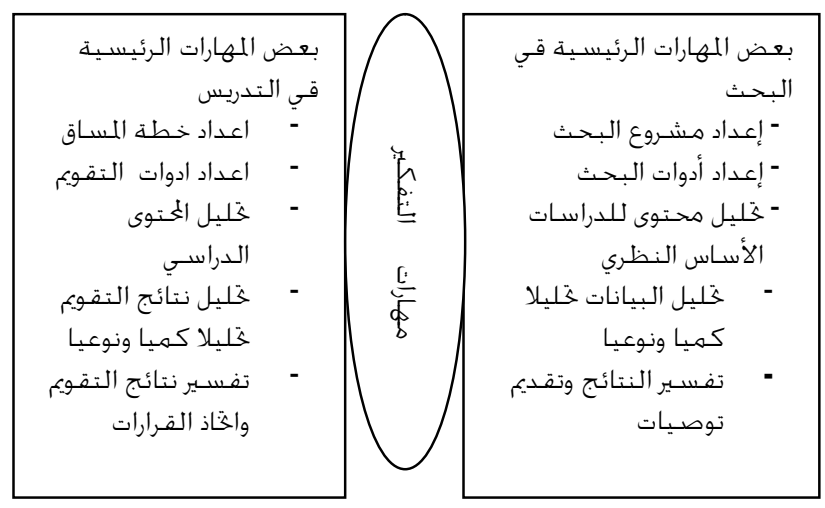

شكل (: مهارات البحث والتدريس

ا. أن البحث العلمي بيئة خصبة وغنية بالمواقف التي تنمي ههارات التفكير، وهي أيضًاً مواقف التف

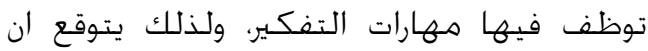

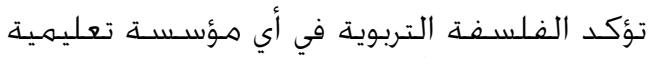

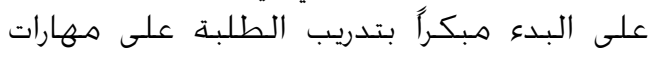
التفكير من خلال طرائق التدريس . وتؤكد أيضاً

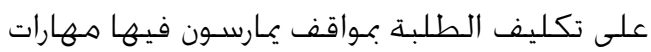

والتعيين والتجديد من جامعة بحثية إلى جامعة

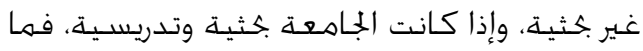

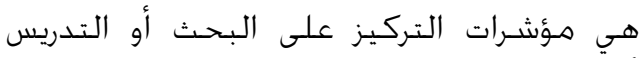

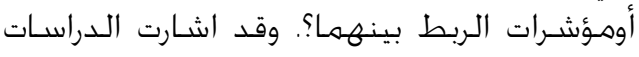

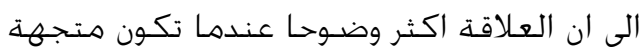

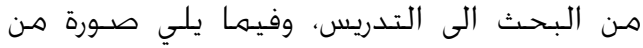

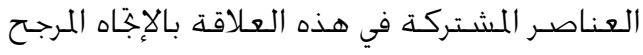

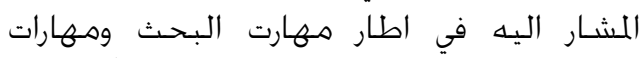

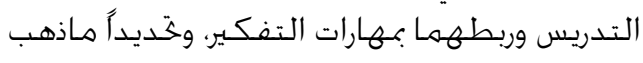
إليه (Lysaker \& Thompson, 2013) الأطر العامة لبعض اوجه هذه العلاقة:

ميتعامل الباحث مع العينات وصدق التمثيل للمجنتمع، ويتعامل المدرس مع عينة الأسئلة في المئي

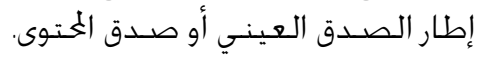

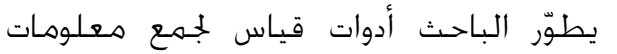

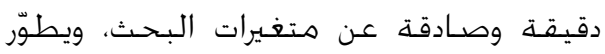
المدرّس أدوات قياس لجمع مع معلوماتهات عن الأداء

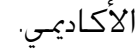

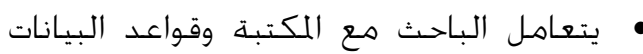

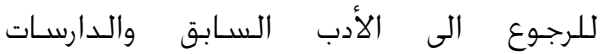

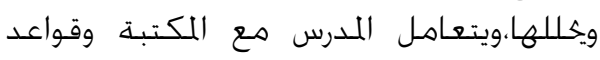
البيانات لإغناء مادة المساق واستراتيجيات للاتيات تـدريســه. • يتعامل الباحث مع الأخطاء المنتظمة والعشـوائية ومصادرها في البيانات البحثية، الاهية ويتعامل المدرس مع نفس الأخطاء ومصادرهات البحان في الدرجات الجامعية. يتعامل الباحث هع الوصف الكهي والبياني

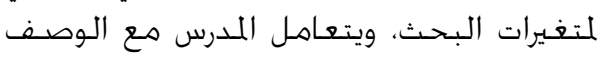

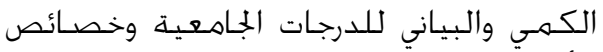

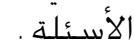
• يتعامل مع الدلالة الرقمية والإحصائية

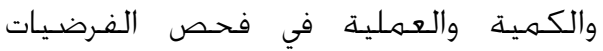

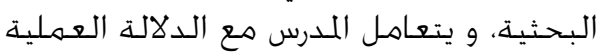

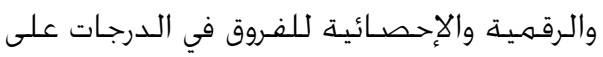

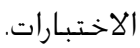

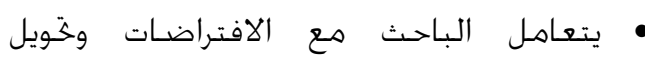
المشـاهدات لتحقيق تلك الافتراضـات، ويتعامل

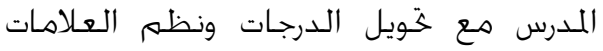
وفحص مدى خَقق الافتراضات التي تبنى الدرجات التهات عليها.

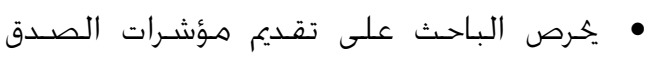

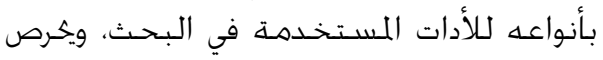


النتيـة المباشـرة أو المعلنة. فالبحـث يعتمد الاستقـصـاء العلمى scientific inquiry.

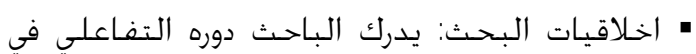

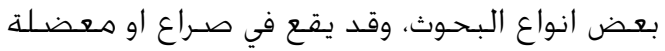

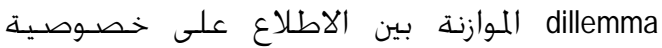

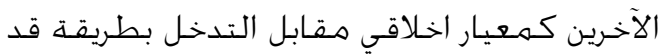

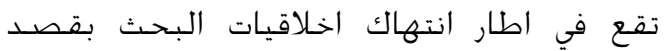

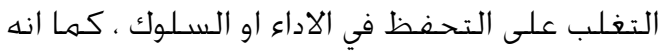

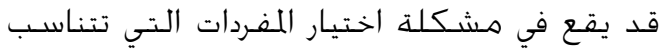

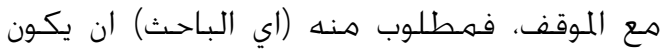

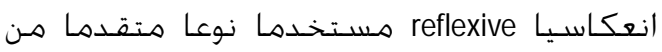

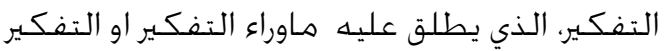

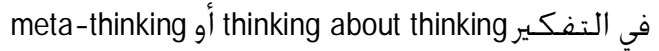

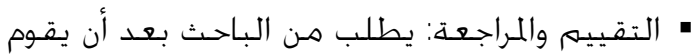
بدوره كباحث أن يترك البحث جانباً ثم يعود ليقـرأ

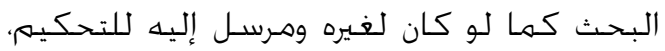

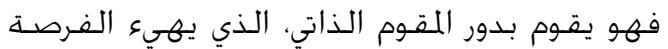

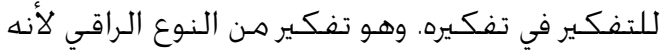

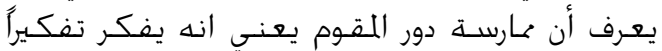

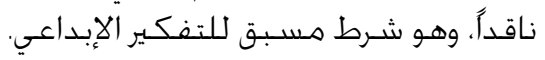
الاسـنتاجات والتوصيات

في ضـوء النتائج والمعاني المشـتقـة مـن الدراسـات السـابقـة

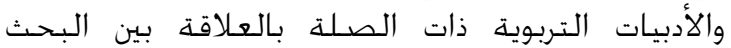

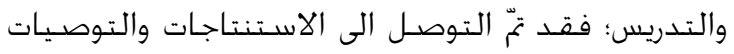
الآتية:

أولا: الاسـتنتاجـات

على الرغـم هـن قدم الجامعات وتزايد الاهتمام

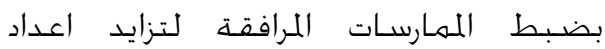

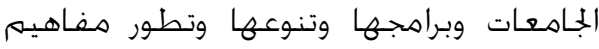

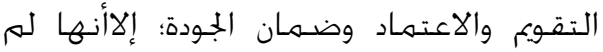

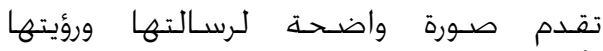
وأهـدافها في اطـار العلاقة بين البحـث والتـدريس.

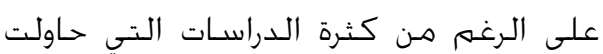

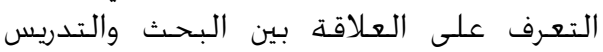

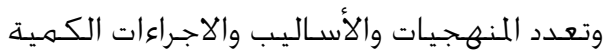

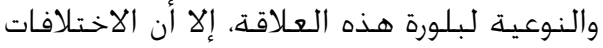

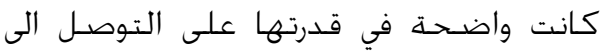

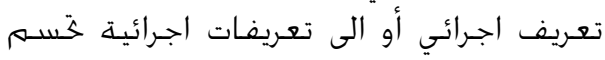
جـدلية هذه العلاقة.

تزايد القـناعة بأن هناك علاقة هـن نوع ما بين

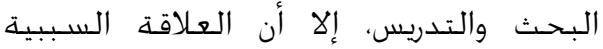

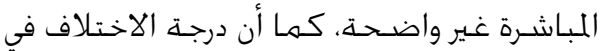

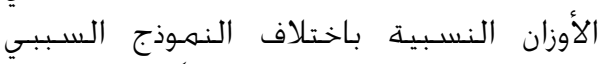
المحتمـل للعـلاقة غير واضـحـة ايضـاً.
البحث العلمي، وختذر هن اكتسـاب معارسـات خاطئة قد يصــب محهوها لاحقـا.

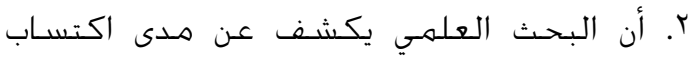

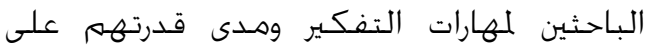
توظيف هذه المهارات في مـواقف بكثيـة حقيقية.

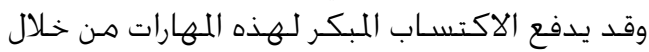

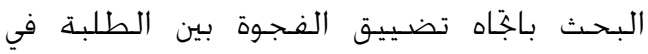

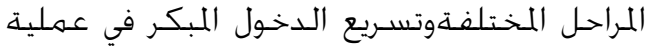

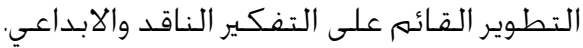

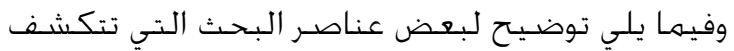

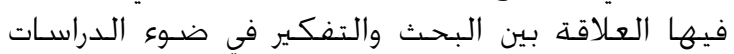

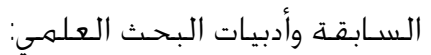

• عنـوان البحث: يبلور العنوان الكثير هـن عناصـر

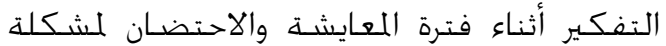

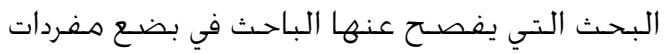

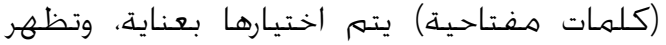

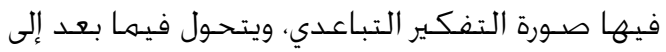

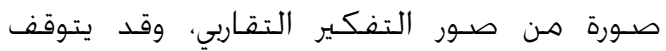

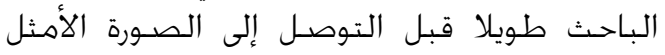
للعنـوان وفق معايير محددة.

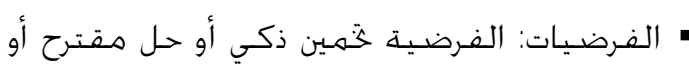

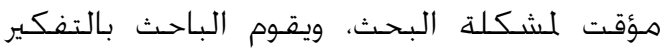

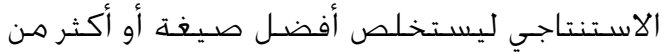

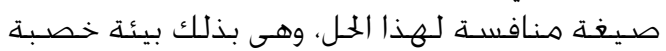
لاستـنبات التفكير.

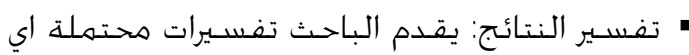

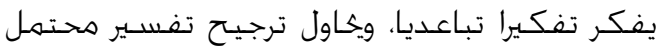

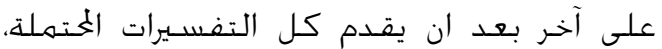

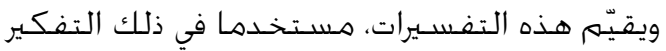

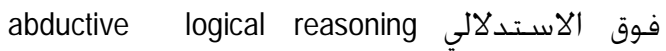
(Lipscomb, 2012)

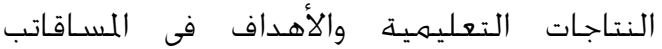

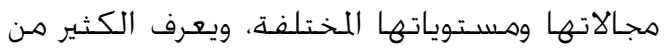

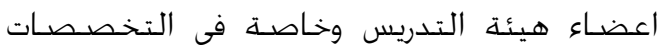

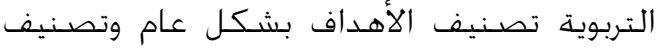
بلوم المعدل Revised Bloom Taxonomy بشـكل خاص والتي يشـكل فيها مستوى (Krathwal, 2002)

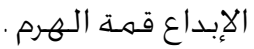
• خَويل البيانات إلى معلوهات: فالباحث يترجهم

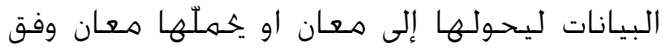

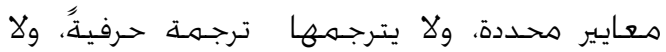

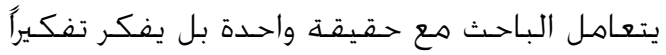

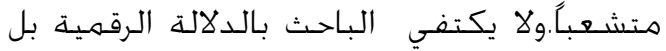

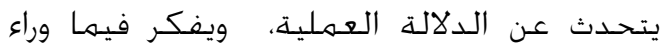




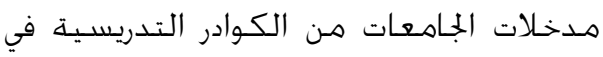

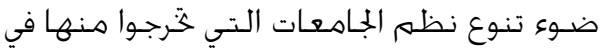

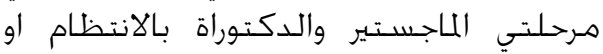

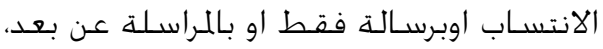
وغسير ذلك هـن الأنظمة التي تفسـح الجال الجسال

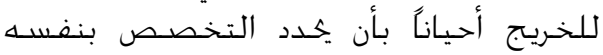

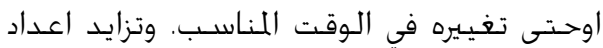

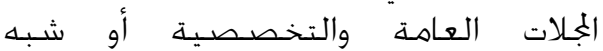
التخصصـية والتطور التكنولوجي ومجالات

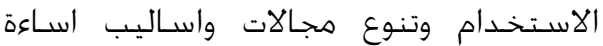

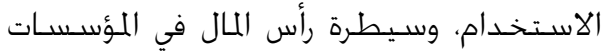

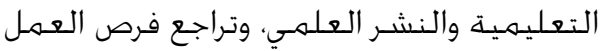

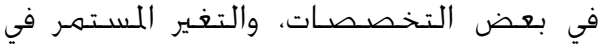

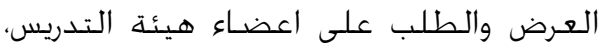

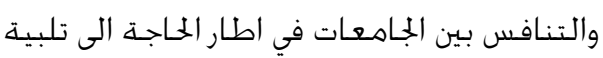

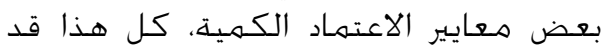

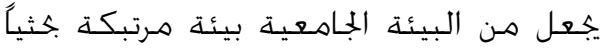

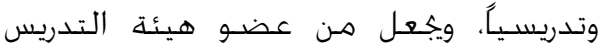

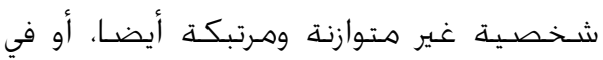

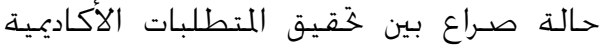

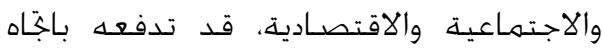

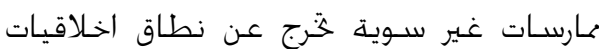

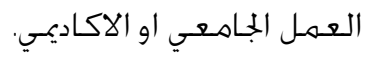

ثانيا: التوصيات

ضـرورة إعادة النظر في معايير ضـمان الجـودة.

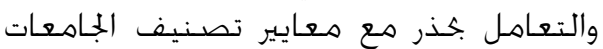

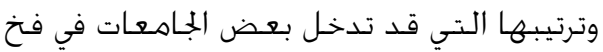

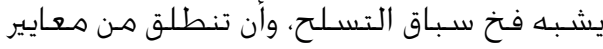

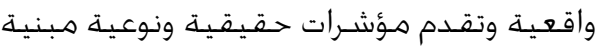

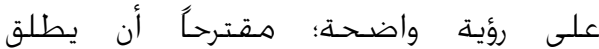

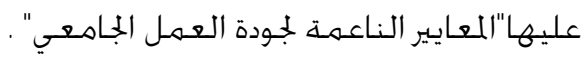

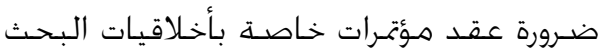

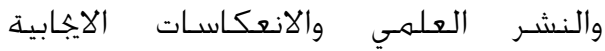

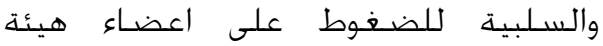
التـريس لإجناز البحـوث ونشـرها بمهواصـفات

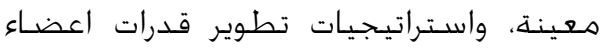
هيئة التدريس وتهيئة الظروف والبيئة الجامعية التي تضـمـن خَقيق الدورين في اطـار

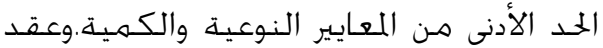

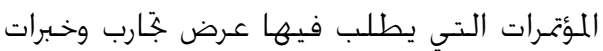
تسـاهم في تقـديم تعريف او تعريفات اجرائية

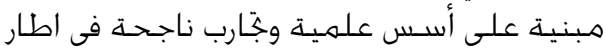
العلاقة بين البحـث والتدريس.
ان عدد ونوع المتغيرات الوسـيطة intermediate ودرجـة مسـاهـمتها في درجـة العـلاقة المباشـرة

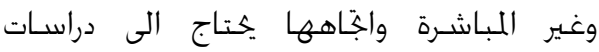

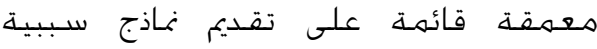
قابلة للفحص، وتشكل (Causal models)

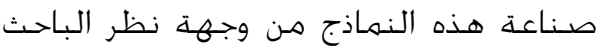
خديًا للباحثين في هـذا الجـال.

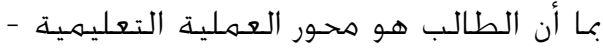

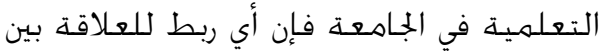

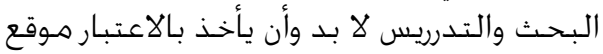

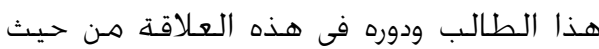

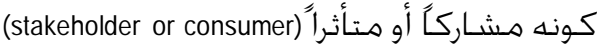

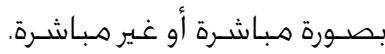
العلاقة بين البحـث والتـدريس قائمهة على ثلاثة

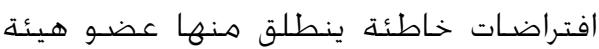
التـريس وهي خطـأ الافتراض التلقـائي بأنه قادر

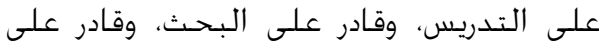
الربط بينهما، ويتوقع مـن الادارات الجامعية أن أن وفئ

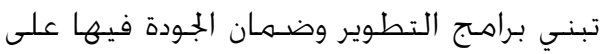

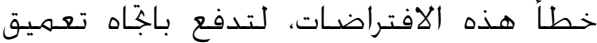

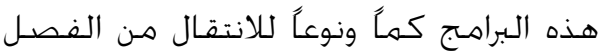

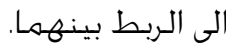
تقـدم الـدراسـات السـابقـة اجابات جـزئية لأسئلة

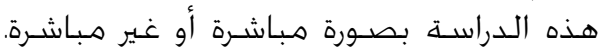

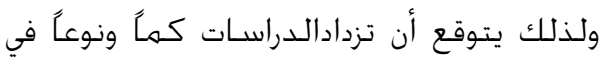
تناولها للعلاقة بين البحـث والتدريس لإنتاج

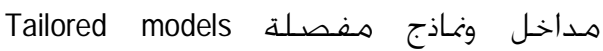

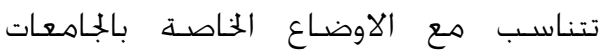

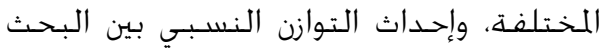
والتدريس لتعظم الاجناز في الدورين.

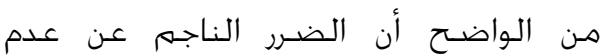

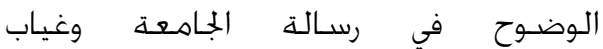

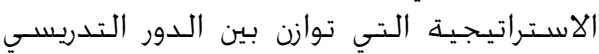

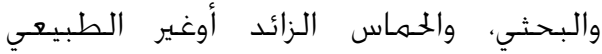

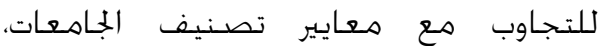

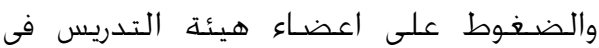
ظروف غير سـوية او غير عادية، قد يدفع بـاجّاه

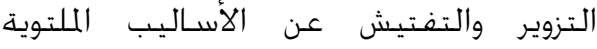

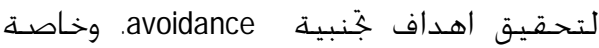

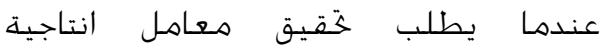
impact factor وتأثير productivity or h-index عاليين (Glanzel, 2006) .(Amin \& Mabe, 2004). إن التزايد في اعداد الجامعات واعداد الطلبة

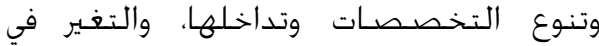


Altbach, P. G. (2012). The globalization of college and university rankings, Change: The Magazine of $\mathrm{H}$ igher learning, 44(1),26-31.

Amin, M., \& Mabe, M. (2004). Impact factors: use and abuse. International Journal of environmental Science and Technology, 1(1), 1-6.Retrieved March, 6, 2013, from

http:/ / www.ceers.org/ ijest/ subscription/ ftacces s.asp

Barnett, R. (2000). Super complexity and the curriculum.Studies in H igher Education, 25(3), 255265.

Benos, D. J. (2005). Ethics and scientific publication.Advances in Physiology Education,29, 59-74.

Bioethics, C. O. (2003).A guide to research ethics. Retrieved September 8, 2012, from University of Minnesota:

http:/ / www.ahc.umn.edu/ img/ assets/ 26104/ Re search Ethics.pdf

Bird, S. J. (2002). Self-plagiarism and Dual and Redundant Publications: What Is the Problem? Science and Engineering Ethics,8, 543-544. Brew, A. (2012). Teaching and research: new relationships and their implications for inquiry-based teaching and learning in higher education. $H$ igher Education Research \& D evelopment, 31, 101-114.

Coate, K., Barnett, R., \& Willioms, Y. (2001).Relationships between teaching and research in higher education in England.Higher Education Q uarterly, 55, 158-174.

Cristina, G. (2001). Undergraduate research, graduate mentoring and the university's mission. Science, 293, 1624-1626.

Cutten, G. (1958). The college professor as teacher. School and Society, 86, 372-375.

Felder, R. (1994). The myth of the superhuman professor. Journal of Engineering Education, 88, 105110.

Feldman, K. (1987). Research productivity and scholarly accomplishment of college teachers as related to their instructional effectiveness: a review and exploration. Research in $\mathrm{H}$ igher Education, 26,227-298.

Glänzel, W. (2006). On the opportunities and limitations of the $\mathrm{H}$-indexl. Science Focus, 1 (1), 1011. Retrieved March 6, 2013, from http:/ / yunus. hacettepe.edu.tr/ tonta/ courses/ s pring2011/ bby704/ H_Index_opprtunities.pdf

Gman, R. (1976). An analysis of the reward structure in two disciplines. Journal of $\mathrm{H}$ igher Education,47, 447465.

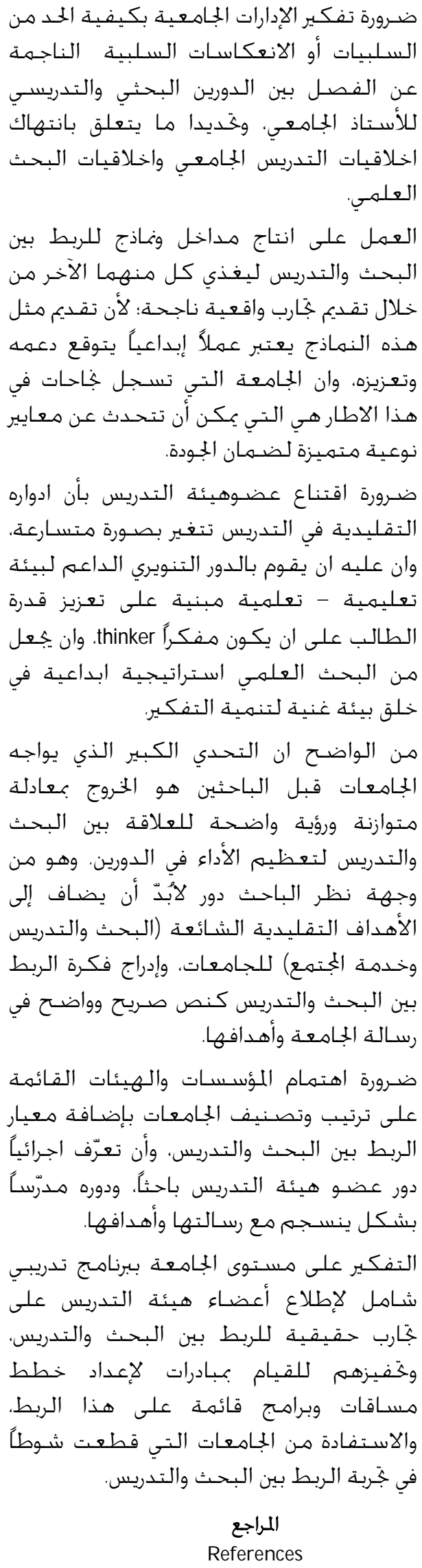

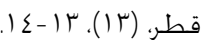


Harry, J., \& Golgner, N. S. (1972).The null relationship between teaching and research.Sociology of E ducation, 45, 47-60.

Healey, M. (2005). Linking research and teaching: exploring disciplinary spaces and the role of inquiry-based learning. In R.Barnett (Ed.). Reshaping the University: New relationship between research, scholarship, and teaching. McGraw Hill, Open University Press, 67-78.

Hendrik, P. Van Dalen, D., \& Henkens, K. (2012). Intended and Unintended Consequences of Publish-or-Perish Culture: A Worldwide Survey. Journal of the AmericanSociety for Information Science and Technology, 1-30. (Retrieved December, 17, 2012 from: arno.uvt.nl/ show.cgi?fid=121469)

Hexler, J. (1969). Publish or perish-a defense. The Public Interest, 17, 60-77. Retrieved N ovember,28, 2012 from:

http:/ / www.national affairs.com/ doclib/ 20060 404_NUMBER017FA LL1969.pdf

Honig, B., \& Bedi, A. (2012). The fox in the hen house: A critical examination of plagiarism among members of the academy of management. A cademy of $M$ anagement Learning $\&$ Education, 11(1), 101-123.

Hunter, A., Laursen, S., \& Seymour, E. (2006). Becoming a scientist: The role of undergraduate research in student's cognitive, personal, and professional development.Science Education, 19, 36-74.

Hurst, B., \& Camp, D. (1999).If you can write a lesson plan you can write an article? Reading Teacher, 53(1) (from: EBSCO database: academic search elite, retrieved. 222/ 10/ 2012).

IDEA center. Research and papers. (selected from a list of 53 papers at the retrieval date) Retrieved 11, March,11 ,2012 from http:/ / www.thei deacenter.org/ .

Integrity, O. O. (2011, March). University of Pittsburgh. Retrieved September 8, 2012, from guidelines for responsible conduct of research: http:/ / www.provost.pitt.edu/ documents/ gui delines\%20for\%20ethical\%20practices\%20in\%2 Oresearch-final revised2-march\%202011.pdf

Jenkins, A., \& Healey, M. (2010). Undergraduate research and international initiatives to link teaching and research. CU R Q uarterly, 30(3), 3642.

Jenkins, A. (2000). The Relationship between teaching and research: where does geography stand anddeliver? Journal of Geography in Higher Education, 24(3), 325-351.
Jenny, H., Wendy, W., \& Richard, S. (2004). Linking teaching and research in the undergraduate fieldworle module: A case study. Planet, 13, 4 7.

Johnson, B., \& Christensen, L. (2004).Educational research, quantitative, qualitative, and mixed approach. Boston: Pearson.

Kiviluoma, P., \& Kuosmanen, P. (2013).M echatronics Education at Aalto University. Retrieved February 28, 2013, from: http:/ / egdk.ttu.ee/ files/ parnu2013/ Parnu_20 13_048-052.pdf.

Kock, N. (1999). Case of academic plagiarism. Communications of the ACM , 42(7), 95-104.

Krathwohl, D. (2002). A Revision of Bloom's Taxonomy: An overview. Theory into Practice, 41(4), 213-218.

Lipscomb, M. (2012). Abductive reasoning and qualitative research.N ursing Philosophy, 13 (4), 244-256.

Lofthouse, S. (1974). Thoughts on "Publish or Perish". Higher Education, 3, 59- 80.

Lysaker, J., \& Thompson, B. (2013). Teacher research as a practical tool for learning to teach. Language A rts, 90(3), 181-191.

Mahani, S., \& Molki, A. (2012).Enhancing the quality of teaching and learning through action research. Journal of College Teaching \& Learning, 9, 209-215.

Marcia, A. (1997). The ethics of clinical research in the third World.The New England Journal ofM edicine, 337(12), 847-849.

Mariken, E., Gerda, J., Roeland, M., \& Jan H. (2009) Mow to strengthen the connection between research teaching in undergraduate university education. H igher Education Q uarterly, 63(1), 64 85.

Mason, P. R. (2009). Plagiarism in Scientific Publications. J infect D eveloping Countries,3, 1-4.

Maureen M., \& Dawson, J. (2006, November). Plagiarism: do students know what it is? Bioscience Education journal, 8. Retrieved September 8, 2012, from http:/ / www.bioscienceheacademy.ac.uk/ jour nal/ vol8/ beej-8-1.aspx.

Melese, W. (2013) Research-teaching link in higher education institutions of Ethiopia: the case of Jimma University. Basic Research Journal of Education Research and Review, 1(6), 85-98.

Messick, S. (1995) Validity of psychological assessment: validation of inferences from 
persons' responses and performances as scientific inquiry into score meaning. A merican Psychologist, 50(9), 741-749.

Neumann. R. (1992). Perceptions of the teachingresearch nexus: A framework for analysis.H igher Education, 23(2), 159-171

Newman, J. (1958). Newman's 'The Idea of a U niversity'. Retrieved October,10, 2012 From: http:/ / www.masmithers.com/ 2010/ 10/ 10/ ne wmans-the-idea-of-a-university/

Norman, J., \& Charles, C. (1976). An Investigation of the relationship among teaching evaluation, research, and ability. The Journal of Economic, 7(2), 77-80.

Office of Research Integrity (2011). Guidelines for responsible conduct of research. (Pitsburge University). Retrieved February, 17, 2013, from http:/ / www.provost.pitt.edu/ documents/ guid elines\%20for\%20ethical\%20practices\%20in\%20resear ch-final revised2 march\%202011.pdf.

Prince, M., Felder, R., \& Brent, R. (2007). Does faculty research improve undergraduate teaching? An analysis of existing and potential synergies.J ournal of Engineering Education, 96(4), 283-294

Rachel, S., \& Rebecca, W. (2010). Can inquiry-based leering strengthen the Links between teaching and disciplinary research. Studies in Higher Education, 35 (6), 723-740

Rams den, P., \& Moses, I. (1992). Association between research and teaching in Australian H igher Education, 23, 273-295.

Rugarcia, A. (1991). The Link between teaching and research: Myth or possibility. Engineering Education, 81, 20-22.

Shah, A. (ed.) (2012). Plagiarism: The bête noire of scientific communication. The Indian Journal of Chest Diseases \& Allied Sciences, 54, 87-89.

Singh, M., Reid, J., Bown, K., Mager, D., \& Santoro, N. (2013). Teacher education, research and the renewal of critique Asia-Pacific Journal of Teacher Education, 41(1), 1-6.

Tuckman, H., \& Hageman, R. (1976).An analysis of the reward structure in two disciplines. Journal of $\mathrm{H}$ igher Education, 47,447-465.

University of Minnesota Center for Bioethics (2003). A guide to research ethics. Retrieved on February 17, 2013, from: http:/ / www.ahc.umn.edu/ img/ assets/ 26104/ Research Ethics.pdf

Wang, W. (2011). A factor analysis study on the mission characteristics of Taiwanese community colleges.Literacy Information and Computer Education Journal (LICEJ), 2 (4), 521531.
Young, J. (2001). Professors publish teaching portfolios online. Chronicle of Higher Education, 147 (49). Retrieved on February 20, 2013, from EBSCO database: A cademic Search premier. 